\title{
Pairs Trading and Spread Persistence in the European Stock Market
}

\author{
Isabel Figuerola-Ferretti* \\ Ioannis Paraskevopoulos ${ }^{\dagger}$ \\ Tao Tang ${ }^{\ddagger}$
}

October 5, 2017

\begin{abstract}
In this paper we adapt the demand and supply framework introduced by FiguerolaFerretti and Gonzalo (Journal of Econometrics 2010) to illustrate the dynamics of pairs trading. We underline the process by which a finite elasticity of demand for spread trading determines the speed of mean reversion and pairs trading profitability. A persistence-dependent trading trigger is introduced accordingly. Applied to STOXX Europe 600 traded equities our strategy exploits price leadership for portfolio replication purposes and delivers Sharpe ratios that outperform the benchmark rules used in the literature. Portfolio performance and mean reversion are enhanced after firm fundamental factor restrictions are imposed.

JEL classification: C58; G11; G12; G14

Keywords: Pairs trading, cointegration, price discovery, error persistence, trading trigger
\end{abstract}

\section{Introduction}

Short-term price discrepancies are common across assets that are imperfectly integrated.

*Business Department, ICADE Universidad Pontificia Comillas, Madrid. E-mail: ifiguerola@comillas.edu

$\dagger$ Capital Markets, Bankia Bank, Madrid. E-mail: iparaskevopoulos@bankia.com

${ }_{\ddagger}^{\ddagger}$ Finance Department, College of Economics, Jinan University, Guangzhou, China. E-mail: taotang@jnu.edu.cn 
Pairs trading strategies are designed to earn profits from relative mispricings of closely related assets. This paper exploits commonalities arising from cointegrated assets to model relative value arbitrage via pairs trading strategies. Pairs trading belongs to the family of convergence trade strategies. It relies on a well-known trading rule for cointegrated price series based on simultaneous long-short positions that are closed when prices revert to a long-run relationship. When an investor opens a position he shorts the out-performer and longs the under-performer, until the mispricing is eliminated. We extend the FiguerolaFerretti and Gonzalo (2010) (FFG thereafter) demand and supply framework to describe price dynamics in two distinct but cointegrated assets and show how market participants exploit temporary mispricings performing pairs trading strategies. The setup requires a finite elasticity of arbitrage services and cointegration error persistence. It evolves around the speed by which arbitrageurs restore equilibrium allowing measurement of price discovery for portfolio replication purposes and arbitrage profit determination. A market is regarded as dominant in this framework if it concentrates a larger number of participants. Cointegration therefore guarantees price convergence that is represented in terms of a stationary error correction term. A trading trigger is derived which is linked to the degree of persistence of the cointegration error so that higher stationarity requires a lower trading trigger.

This paper is related to Gatev et al. (2006) (GGR thereafter), which examines the performance of pairs trading using daily U.S. stock return data. GGR perform pairs selection using the minimum distance algorithm. They find economically and statistically significant excess returns of around 11\% per annum. Following GGR, Andrade et al. (2005), Broussard and Vaihekoski (2012) and Bowen and Hutchinson (2014) apply the algorithm to Asian and European equity markets. A common drawback from these studies is that they essentially apply an ad hoc trading trigger. Vidyamurthy (2004) sheds light to this problem by searching for trading trigger optimality by maximizing a profit function under the assumption of Gaussian errors.

Another strand of the literature models the cointegration spread under dynamic settings. Elliott et al. (2005) and Avellaneda and Lee (2008) consider an Ornstain-Uhlenbeck process 
to model the cointegration error allowing spread estimation and setting the framework for determination of the threshold value. While Avellaneda and Lee (2008) empirically determine cutoff values based on the process assumed for the cointegration error, Elliott et al. (2005) link the trading trigger to the degree of mean reversion. This paper contributes to the literature by adapting the FFG model to paired equity prices to illustrate the process of cointegration error correction by means of an economically meaningful VECM. In doing this, we show that pairs trading profitability is dependent on the error speed of adjustment (or spread mean reversion) which is determined by the elasticity of demand for pairs trading strategies and the total number of market participants. We therefore demonstrate that lower error persistency leads to higher pairs trading profitability. We accordingly propose a trading trigger that is determined by the speed of convergence to the long-run stationary relationship arising from VECM estimates. Our model-based trading rule is therefore related to Elliott et al. (2005) in that the trading trigger is defined as a function of the speed of mean reversion. This is motivated from VECM dynamics as pairs trading profitability is directly dependent on cointegration error persistence which is determined by the speed of mean reversion. This is consistent with the results reported by Kanamura et al. (2010) where an empirical link between profitability and mean reversion is established for spread trading in the gas market. The relationship between the speed of adjustment and the number of participants has been empirically addressed in the literature by Brennan et al. (1993) in an study relating the number of informed traders proxied number of analyst following a firm with the speed of adjustment to common shocks.

Our empirical application is based on an out-of-sample analysis and uses STOXX Europe 600 traded equities whose prices are quoted in the euro currency to identify cointegration relationships with a sample ranging from 2000 to 2017. Common factor and industry restrictions are imposed to illustrate the existence of long-run stationary relationships. This justifies the use of a model with equity shared fundamentals that drive prices to parity. We analyze the profitability of pairs strategies at the portfolio level and compare their performance with benchmark pairs trading methodologies used in the literature. We use price 
leadership for portfolio replication purposes in an extensive out of sample estimation. We find that the proposed pairs strategies outperform the seminal strategy of Gatev et al. (2006), as evidenced by significant abnormal returns and higher Sharpe ratios. The documented outperformance is enhanced once we control for common firm fundamentals as well as the industry effect.

The rest of the paper proceeds as follows. In Section 2 we relate the VECM dynamics to the construction of pairs trading strategies. This requires a description of preliminaries and main results of the FFG model applied to two distinct but cointegrated assets. Section 3 presents the data sample and empirical results on cointegration and price discovery. In section 4 we conduct the pairs trading performance analysis with a number of robustness tests developed to illustrate the outperformance of our model-based approach. Section 5 provides conclusions.

\section{The theoretical model}

\subsection{Model set-up}

The aim of this section is to introduce pairs trading strategies in a demand and supply framework. Paired firms in this context share common fundamentals and are linked via longrun stationary relationships generated by market forces. Accordingly, arbitrage takes place through pairs trading strategies that exploit mean reversion of pricing errors. Convergence takes place because paired assets measure a common underlying factor. The model is built on the presumption that price correction of two cointegrated assets departing from long-term stationary relationships depends on the average speed of convergence in each market. This determines the degree of persistence of the cointegration error and becomes an important factor for both the trading trigger and for profit determination.

In what follows we present the joint dynamics between two cointegrated assets within a demand and supply market clearing framework. Investors either take single asset positions or trade two assets that share common fundamentals simultaneously via the use of pairs trading 
strategies. Mean reversion of the cointegration spread is of critical importance to arbitrageurs who, will exploit short-lived deviations in search of profitability from pairs strategies. Under imperfect integration, there is a finite elasticity of demand for arbitrage services $(H),{ }^{1}$ and relative prices may differ between markets for short intervals of time by more than transaction costs. The speed by which such price discrepancies are eliminated depends on the degree of persistence in the error term $z_{t}$. The speed of mean reversion is determined by market imperfections that represent impediments to arbitrage such as liquidity or potential funding constraints. $^{2}$

We extend the FFG model to describe the mean reversion framework for imperfectly integrated markets allowing for persitency in the cointegrating error. Let $y_{t}$ and $x_{t}$ be the price of paired assets in time $t$, respectively. In order to find the non-arbitrage stationary condition, the following set of standard assumptions applies in this section:

1. No limitations on borrowing.

2. No cost other than arbitrage transaction cost.

3. No limitations on short-sale.

4. Arbitrage opportunities that generate a random price difference between paired assets are determined by the stationary process $z_{t}$ (also denoted as the price spread). These arise as a result of market imperfections that impede arbitrage opportunities between markets and lead to a finite elasticity of demand for pairs trading strategies $(H>0)$ and a stationary cointegration error. ${ }^{3}$

5. The equity price series $y_{t}$ and $x_{t}$ are $I(1)$, implying that their mean and auto-covariance are different for every realization of $t$.

By the above assumptions 1-5, there exists a long-run stationary relationship described by:

\footnotetext{
${ }^{1}$ This elasticity measures the proportional change in demand for arbitrage strategies in the form of "pairs trading" for a given change in the quantity of arbitrage services.

${ }^{2}$ See for instance Shleifer and Vishny (1997), Xiong (2001), Gromb and Vayanos (2002) and Kondor (2009) for a detailed discussion on the limits to arbitrage.

${ }^{3}$ Market imperfections lead to stationary cointegration errors and finite elasticity of arbitrage services. This differs from other frameworks in the literature that have considered non linearities in the cointegration error to identify the presence of non linearities within the basis term arising under the presence of transaction costs, or interaction between sentiment and trading behavior. See McMillan and Ülkü (2009).
} 


$$
y_{t}=\gamma_{0}+\gamma_{1} x_{t}+z_{t}
$$

where $\gamma_{0}$ is the (constant) cash amount invested (or borrowed) to buy $\gamma_{1}$ units of asset $x_{t}$ (required to replicate prices of asset $y_{t}$ ). Therefore $\gamma_{1}$ is the hedge ratio as it reflects the size of position that has to be taken in the portfolio with asset $x_{t}$ to replicate the prices of asset $y_{t}$. Equation (1), implies that $y_{t}$ and $x_{t}$ are cointegrated suggesting (imperfect) market integration. Pairs trading strategies are triggered when temporary mispricings arise from the long-run cointegration relationship. When the spread between $y_{t}$ and $x_{t}$ widens by an amount higher than a given threshold, there is a positive profit potential that can be exploited by an arbitrageur who shorts the winner and buys the loser. If the long and short components measure common fundamentals, the prices will mean revert to the longterm relationship providing positive average (and cumulative) profits. This framework is consistent with Brennan and Schwartz (1990) arguing that it is market imperfections that give rise to the arbitrage opportunity.

The model developed in Appendix A describes the dynamics of agents who trade single securities and agents who trade two cointegrated assets. Market imperfections are in this context translated into a finite elasticity of demand for pursuing pairs strategies. The demand schedule for each traded asset has two components: (a) the own asset demand and (b) the speculative demand based on the long-term relationship between the two traded assets. Market clearing conditions are defined by equating aggregate market demand and aggregate supply schedules in a context where new information arrival is reflected in the difference between lagged market clearing prices and current bid prices. The resulting bivariate dynamics between $y_{t}$ and $x_{t}$ are represented by the following VECM:

$$
\left(\begin{array}{c}
\Delta y_{t} \\
\Delta x_{t}
\end{array}\right)=\frac{H}{d}\left(\begin{array}{c}
-N_{x} \\
N_{y}
\end{array}\right)\left(\begin{array}{lll}
1 & -\gamma_{1} & -\gamma_{0}
\end{array}\right)\left(\begin{array}{c}
y_{t-1} \\
x_{t-1} \\
1
\end{array}\right)+\left(\begin{array}{c}
u_{t}^{y} \\
u_{t}^{x}
\end{array}\right)
$$

with 


$$
d=\left(H+A N_{y}\right) N_{x}+\gamma_{1} H N_{y}
$$

where there are $N_{y}$ participants in the market for asset $y_{t}$ and $N_{x}$ participants in the market for asset $x_{t}$ and, as previously specified, the elasticity of demand for pursuing pairs strategies is noted by $H$.

The model therefore shows how demand and supply market clearing conditions lead to a meaningful VECM framework for pairs trading. The concept of reversion to the long-run relationship in this context is ideal to illustrate the pairs trading process. Note that pairs trading strategies require a finite elasticity of demand for pairs trading strategies $(H)$. Higher market imperfections are translated into more persistent errors and lower $(H)$. In the limit, when arbitrage opportunities are exploited instantaneously, there is an infinite elasticity of demand for pairs trading strategies $(H \rightarrow \infty)$. This leads to immediate price adjustments in the two cointegrated markets, implying that temporary mispricings disappear and $z_{t}=0$. In this case the relationship $\left(y_{t}=\gamma_{0}+\gamma_{1} x_{t}\right)$ becomes an exact relationship. When $(H=0)$ $y_{t}$ and $x_{t}$ become independent $I(1)$ processes there is no VECM model and profits from pairs trading become zero.

We rewrite the theoretical result in (2) as:

$$
\Delta P=\left(\begin{array}{c}
\Delta y_{t} \\
\Delta x_{t}
\end{array}\right)=\left(\begin{array}{c}
\alpha_{1} \\
\alpha_{2}
\end{array}\right) z_{t-1}+u_{t}
$$

where $u_{t}$ is a vector white noise with i.i.d shocks. ${ }^{4}$ If the VECM is to be well defined so that we can guarantee that "pairs strategies" can be applied, the following conditions need to be satisfied:

1. If $\alpha_{1}$ and $a_{2}$ are both statistically significant, they must have opposite signs, as predicted by the theoretical result in (2). This implies that, if there a significant change in the cointegration error, so that for instance $y_{t}$ is greater than its replicating portfolio

\footnotetext{
${ }^{4}$ Note that in the empirical part lags of $\Delta P$ are chosen in order to obtain white noise errors.
} 
$\left(\gamma_{0}+\gamma_{1} x_{t}\right)$ by a given threshold value $(T V)$, i.e. $\left(z_{t}>T V\right)$, in order to restore the long-term relationship $y_{t}$ is required to fall in the next period while $x_{t}$ is expected to increase. In this case, $\alpha_{1}$ will be negative, $\frac{H}{d}\left(-N_{x}\right)$, and $\alpha_{2}$ positive, $\frac{H}{d}\left(N_{y}\right)$, so pairs strategists will short $y_{t}$ (outperformer) and buy $x_{t}$ (underperformer) to exploit price divergences. This allows positive profits until temporary mispricing vanishes. Conversely when $\left(z_{t}<-T V\right)$, asset $x_{t}$ is overpriced in $t$, which implies that $\alpha_{2}$ will be negative $\frac{H}{d}\left(-N_{y}\right)$ and $\alpha_{1}$ will be positive $\frac{H}{d}\left(N_{x}\right)$ to guarantee mean reversion of the error term. The determination of the $T V$ is described in Section 2.2 below.

2. If $z_{t}>0$ and the asset $y_{t}$ was contributing significantly to price discovery, $\alpha_{2}$ will be positive and statistically significant as the asset $x_{t}$ adjusts to incorporate new information. Similarly, if the market trading $x_{t}$ is an important venue for price discovery and liquidity then $\alpha_{1}$ would be negative and statistically significant. If both coefficients are significant then both markets contribute to price discovery. The existence of cointegration means that at least one market has to restore the long-run relationship, indicating that the given market is under (over) priced and is short-term inefficient. Profits from pairs strategies can therefore be achieved. If the adjustment of both prices is immediate and independent of the cointegration error $\left(\alpha_{1}=\alpha_{2}=0\right)$, the elasticity of demand for pairs strategies is infinite $(H \rightarrow \infty)$, and there is no VECM, no price discovery, and no profit from pairs strategies. ${ }^{5}$

3. In the VECM framework, the paired assets are modeled to converge to each other to restore the long term relationship. The coefficients $\alpha_{1}$ and $a_{2}$ are the adjustment coefficients, and measure the speed of error correction. This is slow when the parameter is close to 0 , and fast when it is close to 1 . In terms of our theoretical framework, $x_{t}$ does not adjust to asset $y_{t}$ when $N_{y}=0$ and $N_{x}>0$. In this case $\alpha_{1}=1, \alpha_{2}=0$ and $x_{t}$ becomes a random walk. Asset $x_{t}$ is essentially the common factor or efficient price. (The reverse is true when $N_{x}=0$ and $N_{y}>0$.).

\footnotetext{
${ }^{5}$ In this case both markets are perfect substitutes and prices are "discovered" in both markets simultaneously. The model is not sustainable for this case.
} 
4. Pairs trading strategies require stationarity of the error term. The error correction mechanism links directly the adjustment speed of paired series to the cointegration error, which follows an autoregressive (mean-reverting) process specified as:

$$
\begin{gathered}
z_{t}=\left(1-\left(-\alpha_{1}+\gamma_{1} \alpha_{2}\right)\right) z_{t-1}+u_{t}^{y}-\gamma_{1} u_{t}^{x} \\
z_{t}=\rho z_{t-1}+u_{t}^{y}-\gamma_{1} u_{t}^{x}
\end{gathered}
$$

In this context, the sum of the absolute values of $\alpha_{1}$ and $\alpha_{2}$ determines the persistence of the cointegration error. In the limit, when $\alpha_{1}=\alpha_{2}=0, z_{t}$ is $I(1)$, there is no cointegration and it is not possible to benefit from trading paired assets. ${ }^{6}$ When $\alpha_{1}$ and/or $\alpha_{2}$ are statistically different from zero and correctly signed (see point 1), the error term will be mean reverting and pairs trading will be profitable. Note that incorrect estimated signs for $\alpha_{1}$ and $\alpha_{2}$ signals explosive behavior in the error term $(\rho>1)$.

In order to describe profits from pairs strategies we define the cointegration error as:

$$
z_{t}=y_{t}-\gamma_{0}-\gamma_{1} x_{t}
$$

Whenever the cointegration error reaches the model trigger so that $y_{t}$ on the previous period is above its long-term level, there will be an arbitrage opportunity which requires that the investor shorts $y_{t}$ in the same amount as the replicating portfolio (constructed with asset $x_{t}$ ) in order to profit from pairs strategies. Profits from this strategy may be defined as:

$$
\Pi_{t}=M\left(-\Delta y_{t}+\gamma_{1} \Delta x_{t}\right)=-M \Delta z_{t}
$$

where $\Pi_{t}$ are measured in $€, y_{t}$ and $x_{t}$ represent equity prices in $€$, and $M$ is the amount invested (in $€$ ). Portfolio replication is defined in terms of price levels (and not returns) and the delta or hedge ratio for a short position in asset $y_{t}$ will be $\gamma_{1}$ implying that $\gamma_{1}$ units of asset $x_{t}$ are acquired to replicate the value of asset $y_{t}$. Portfolio allocations are

\footnotetext{
${ }^{6}$ The absolute value of the estimated adjustment coefficients has to lie between 0 and 1 . A proof of this statement can be provided upon request.
} 
therefore determined according to the regression coefficients of the cointegration relationship. Substituting the result in Equation (4), we get :

$$
\begin{aligned}
\Delta y_{t} & =\alpha_{1} z_{t-1} \\
\Delta x_{t} & =\alpha_{2} z_{t-1} \\
\Pi_{t} & =M\left(-\alpha_{1}+\gamma_{1} \alpha_{2}\right) z_{t-1}
\end{aligned}
$$

From Equation (6) we can write :

$$
\Pi_{t}=M(1-\rho) z_{t-1}
$$

Profits are therefore negatively related to error persistence so that a more stationary the error term leads to higher pairs trading profitability. When $\rho>1$, the cointegration spread is explosive and profits become negative.

When $z_{t-1}>0$, asset $y_{t}$ is overpriced in period $t-1$. This indicates that in time $t$ as previously specified, under VECM dynamics, $\alpha_{1}$ must be negative, and $\alpha_{2}$ positive as they move to restore equilibrium. Therefore we have:

$$
\Pi_{t}=M \frac{H}{d}\left(N_{x}+\gamma_{1} N_{y}\right) z_{t-1}
$$

where

$$
d=\left(H+A N_{y}\right) N_{x}+\gamma_{1} H N_{y}
$$

In this framework, expected theoretical profits from pairs strategies are always positive. Profits are increasing in $(H)$ and in the size of arbitrage opportunities as reflected in the cointegration error. Whenever $H=0$ there is no profitability from pairs trading strategies. Profits can also be related to the total number of participants. When the total number of market participants is zero $N_{x}=N_{y}=0$ profitability becomes also zero. If $N_{y}=0$ and $N_{x}>0$ then $\alpha_{1}=1, \alpha_{2}=0$. From equation (9) we have that $\Delta x_{t}=0$ so pairs trading profitability wil be defined by 


$$
\Pi_{t}=M \Delta y_{t}=M z_{t-1}
$$

Note that profitability in this case becomes independent of the elasticity of demand for pairs trading and the number of participants in the two markets. The same applies to the analogue case $N_{x}=0$ and $N_{y}>0$ then $\alpha_{1}=0,1$.

\subsection{Threshold design for the cointegration error}

The trading algorithm dictates that arbitrage opportunities will be exploited when $z_{t}$ exceeds a given threshold value $T V$. Under these circumstances the general principle is applied. This requires placing a new trade when the error deviates from the long-term relationship and unwinding the trade when this relationship is restored. In order to optimally design the trading trigger, one has to specify what would qualify as a sufficient divergence of the cointegration error from its long-term level. The literature does not offer a closed form solution to this question. Instead, it demonstrates that the actual implementation of the trading algorithm is wide and varied (see Park and Switzer (1996), Avellaneda and Lee (2008), Elliott et al. (2005) and Vidyamurthy (2004) for description of threshold possibilities).

Park and Switzer (1996) perform basis trading in the fixed-income market and define the trading trigger in terms of a combination of a moving average and a standard deviation calibrated with a tolerance parameter. Avellaneda and Lee (2008) estimate trading cutoffs based on mean reversion of a dimensionless variable while Vidyamurthy (2004) proposes various band designs for different assumptions regarding the spread process. Our approach is consistent with Vidyamurthy (2004) and Elliott et al. (2005) in that we define the threshold value in terms of the amount of volatility $(\sigma)$ away from the mean. However we exploit the model-based result relating lower persistence to higher profitability as outlined in Equation (10) to define the calibrating parameter of the trading trigger. Using the results underlying Equation (5) we propose $\rho \sigma=\left(1+\alpha_{1}-\gamma_{1} \alpha_{2}\right) \sigma$ as the model threshold.

Therefore the calibration parameter $\rho$ measures the number of standard deviations of $z_{t}$ from its mean that triggers a trade. In this way we link the model threshold to the 
persistence of the error term so that more persistent errors require a higher threshold. Under this framework a trade will be triggered when $\left\|z_{t}\right\|>\rho \sigma$ and unwound when the long-run level is restored so that $\left\|z_{t}\right\| \leq \rho \sigma$. Note that from Equations (2) and (4) we can define the speed

of adjustment estimates $\left(\alpha_{1}\right.$ and $\left.\alpha_{2}\right)$ in terms of our model parameters so that $\alpha_{1}=\frac{H}{d}\left(-N_{x}\right)$ and $\alpha_{2}=\frac{H}{d}\left(N_{y}\right)$. This implies that, under the proposed theoretical model, the trigger will have a value equal to one $(\rho=1)$ when the elasticity of demand for arbitrage strategies is zero $(H=0)$ and/or when the total number of participants is zero $\left(N_{x}=N_{y}=0\right)$. As the elasticity becomes larger and the sum of market participants increases, the threshold value decreases. The parameters illustrating mean reversion are therefore crucial to the trading process. For this reason, the trading trigger is dependent on the persistence of the cointegration error and on mean reversion. Note that this is in line with Elliott et al. (2005), who inversely relate the trigger level to the speed of convergence in the spread. Our work is also consistent with Kondor (2009). In particular Kondor (2009) demonstrates that returns are a decreasing function of the trading window. In our setting, more persistent errors are likely to require longer trading windows when a trade is opened. To deal with this problem our framework requires higher threshold for persistent errors. Higher profitability requires lower thresholds. Therefore persistent errors require a higher trading threshold to guarantee profitability when there is mean reversion in the cointegration process. Strong stationarity of the error term is associated with lower triggers.

The threshold is also linked to pairs trading profitability as underlined in Equations (10) and (11). The link between mean reversion and profitability has been discussed in the literature by Kanamura et al. (2010) who report an empirical link between them for spread trading in the gas market.

\subsection{Portfolio replication}

Portfolio replication requires determination of price leadership in the context of price discovery. In this framework the dominant price is used to replicate the value of the follower. Price discovery measures the contribution of cointegrated assets to reveal information regarding 
a common factor that measures fundamentals. ${ }^{7}$ It can be shown from VECM in $(2)-(4)$, that the contribution of assets $y_{t}$ and $x_{t}$ to price discovery is:

$$
\begin{aligned}
& P D_{y}=\frac{\alpha_{2}}{\alpha_{2}-\alpha_{1}}=\frac{N_{y}}{N_{y}+N_{x}} \\
& P D_{x}=\frac{-\alpha_{1}}{\alpha_{2}-\alpha_{1}}=\frac{N_{x}}{N_{y}+N_{x}}
\end{aligned}
$$

Following the FFG framework the common factor is defined as:

$$
C F=P D_{x} x_{t}+P D_{y} y_{t}
$$

If new information from both markets is incorporated into the common efficient price, $0 \leq P D_{i} \leq 1$ for $i=y, x$. Under the extreme case where $\alpha_{1}=0$, the price discovery metrics become $P D_{y}=1$ and $P D_{x}=0$ then there is a predominance of asset $y_{t}$ in the price discovery process. ${ }^{8}$ If $\alpha_{2}=0$ then we have $P D_{x}=1$ and $P D_{y}=0$ so that there is a predominance of asset $x_{t}$ in terms of price discovery. Price discovery is exploited so that the leading asset is used in this model to replicate the value of the follower. Equations (13) and (14) demonstrate that price discovery relies on the relative number of agents in both markets which defines the relative speed of mean reversion.

\section{Cointegration and price discovery}

In this paper we focus on the European equity market in order to identify cointegration and potential profitable opportunities underlying pairs trading strategies. We consider companies included in the STOXX Europe 600 index. Given that the STOXX Europe 600 Index represents large, mid and small capitalization companies across 17 countries of the European region we restrict the analysis to those corporates that are located in the Eurozone such that their prices are quoted in euro currency. The selected sample consists of 292 companies

\footnotetext{
${ }^{7}$ See Hasbrouck (1995), Gonzalo and Granger (1995), and Lehmann (2002).

${ }^{8}$ Predominance in this context implies that the common fundamental factor is driven solely from the dominant price.
} 
across 10 countries of the European common currency area.

In what follows we perform a cointegration analysis to identify pairs that converge to a long-term relationship over time. The finding of cointegration between two equity prices implies that they measure a common underlying factor reflecting market fundamentals as underlined in Equation (15). Price discovery in this context quantifies the contribution of each of the cointegrated series to the revelation of the common factor. Commonalities between paired firms give rise to a cointegration error as exhibited in the long-run stationary relationship underlined in Equation (1). The idea is that paired assets converge to this relationship over time. Under our baseline analysis commonalities arise for the following underlying reasons: (a) Firms belong to the same trading and currency area. They are therefore subject to similar sources of market risk and face common regulation. (b) Firms operate under the same sector and therefore share industry risks as well as market risk. (c) Firms are likely to share R\&D intensities. ${ }^{9}$ Under this framework pairs that are found to be cointegrated are linked via a long-term linear relationship which prevails due to arbitrage between the paired assets. Additional firm related fundamentals are considered in Section 4.5 .

Daily closing price data are collected over the period dating from January 1st, 2000 to February 6th, 2017. This comprises an average of 4461 trading observations ${ }^{10}$. The data source is Datastream. Our sample period covers the pre-crisis period as well as the post Lehman era, therefore it allows us to analyze pairs trading under the existence of cointegration in different market states. The presence of cointegration indicates that two nonstationary $I(1)$ variables have a linear combination that is stationary, $I(0)$. In what follows, we identify a matching partner for each stock with the restriction that both stocks should belong to the same industry. According to the Industry Classification Benchmark used by STOXX indices ${ }^{11}$, the 292 companies are categorized into ten industries, namely, Financials (63), Industrials (58), Consumer Goods (42), Consumer Services (33), Basic Materials (23),

\footnotetext{
${ }^{9}$ See Hyunbae et. al. 2004

${ }^{10}$ Note that not all companies have the same starting date.

${ }^{11}$ This classification is based on the companies' primary revenue source.
} 
Utilities (20), Health Care (16), Technology (15), Telecommunications (11), and Oil \& Gas (11). The model presented in Section 2 demonstrates that the mechanism behind cointegration lies on the existence of an underlying common efficient price. Our empirical analysis is based on the VECM specified in Equation (4). Econometric details of the estimation and inference of (4) can be found in Johansen (1995) and Juselius (2006).

We start by performing an Augmented Dickey-Fuller test as unit roots are a necessary condition for cointegration. We fail to reject the null hypothesis of a unit root for all price series analyzed. We perform the Johansen cointegration test using a rolling-window approach within a given industry at the $5 \%$ significant level. Specifically, we use a three-year window from $t$ to $t+3$ (estimation period) to identify cointegrated pairs and, for each selected pair, estimates of the cointegration vector in the VECM are obtained. The selected pairs and resulting estimates are then applied to trading implementation (see the detailed description in Section 4.1) for the next six-month window from $t+3$ to $t+3.5$ (trading period). This procedure is repeated through the remaining sample period. This leaves us, for instance, with the second estimation window from $t+0.5$ to $t+3.5$, which is followed by the trading window from $t+3.5$ to $t+4$. Given that not all companies have been listed at the first sample date, January 1st, 2000, the starting date of a possible pair is chosen so that transactions are available on both corporates considered. The resulting paired equities are tied via a long-run arbitrage relationship under the imposed restriction that the error term is stationary. Paired equities are in this sense close substitutes, and they tend to move in synchrony.

Once cointegration relationships are estimated, we investigate the lead-lag relationship for each pair to determine which asset dominates the price discovery process. Table 1 reports VECM estimates across industries. Because there are thirty different rolling samples, reported results represent an average value computed from a series of estimates for each percentile. We find from Panel A that the adjustment coefficient $\alpha_{1}$ is significantly negative for all industry percentiles, ${ }^{12}$ suggesting that the price of the follower $\left(y_{t}\right)$ is expected to drop by $\alpha_{1}$ units in response to one unit increase in the error correction term. The corresponding

\footnotetext{
${ }^{12}$ Average standard errors by industry can be provided upon request.
} 
estimate of $\alpha_{2}$ is positive under all percentiles. Results of $\alpha_{2}$ also suggest that it is not significantly different from zero in $80 \%$ of the estimations. This implies that there is an asymmetric lead-lag relation in $80 \%$ of the paired corporates. For the remaining 20\%, both assets contribute to price discovery. However, the general result is that there is a dominant asset $\left(x_{t}\right)$ relative to its matching partner $\left(y_{t}\right)$ in terms of price discovery, and thus the follower $\left(y_{t}\right)$ does all the adjustment to restore the long-term relation. Note that this result comes by construction given that the leading asset $\left(x_{t}\right)$ is used to replicate the follower $\left(y_{t}\right)$. Effectively Johansen cointegration estimates are obtained in a context in which the follower (or the dependent variable) is set to be explained by the leader which acts as the independent variable. The existence of cointegration allows using Maximum Likelihood estimators of the cointegrating relation to build our portfolio strategy, instead of OLS regressions as widely used in the statistical arbitrage literature ${ }^{13}$. The (constant) cash amount, $\gamma_{0}$, is required to be positive ${ }^{14}$. The positive sign of $\gamma_{0}$ suggests that long cash positions should be held to replicate the follower with $\gamma_{1}$ units of the leading asset, and thus interest expenses are omitted from the construction of arbitrage profits. Then we look at the estimated values of $\gamma_{1}$ reported in Panel B. The values are varied as different units of the leading asset are required to replicate the follower. Note that the largest range for $\gamma_{1}$ is for Financials and Industrials, the two sectors with highest number of paired companies. This coefficient reflects the sensitivity of one asset to its matching partner and is in essence the hedge ratio in our pairs trading strategy.

\section{Profitability of pairs trading}

\subsection{Model-based pairs trading strategies}

In this section, we illustrate the proposed pairs trading mechanism presented in Section 2, based on the existence of cointegration. The trading mechanism is described as follows:

\footnotetext{
${ }^{13}$ see for instance Schaefer and Strebulaev (2008) and Kapadia and Pu (2012).

${ }^{14}$ Estimated values of $\gamma_{0}$ can be provided upon request.
} 
An arbitrageur opens a long-short position on the day following departure, when the price spread hits the model-derived threshold, denoted as $\left(1+\alpha_{1}-\gamma_{1} \alpha_{2}\right)$ units of standard deviation calculated from historical spreads. The initial position is then unwound one day later when price reversion eventually occurs, or is forced to close at the end of a 6-month trading period if no convergence takes place. In other words, we trade according to the rule that delays the opening/close of a position by one day, and the maximum trading horizon is six months. After a pair has completed a round-trip trade, it will be subject to the identical trading rule again. As previously discussed, this paper applies a three-year rolling-window approach. This results in a series of cointegration coefficients and speed of mean reversion estimates. These estimates are used to determine pricing errors to design the following sixmonth out-of-sample trading strategies. The implementation of trading requires construction of replicating portfolios and trading triggers immediately following the three-year estimation period. Since most data are available from January 1st, 2000, their first valid trading day is the first business day in January 2003.

This trading mechanism, which longs the underpriced asset and shorts the overpriced one simultaneously, is implemented according to the sign of the estimated alpha coefficients. Theoretical profits are always positive and defined by return differentials as specified in Equations (8) and (9). Our pairs selection algorithm is driven by cointegration, which implies that profits generated by the proposed strategy are expected to be stationary. We therefore identify mean reverting spread portfolios that deliver stationary profits. Stationarity in this context implies that the fundamental related risk is hedged. As stated in the model, cointegration guarantees that short-lived price deviations revert towards the long-run level, such that the slow adjustment process can be exploited to make profits. With this trading rule Figure 1 illustrates how to perform the strategy using the cointegrated pair, Air Liquide and BASF, as an example. The fluctuating line in blue represents price spread $z_{t}$, while the two straight lines in green indicate the borders of model-derived threshold (either positive or negative). The line in grey, near to the $\mathrm{x}$-axis, reflects the opening and close of pairs trades on a daily basis. We see that a position is initiated when the price spread moves beyond the 
border and then closed when price deviation lies between two border lines.

\subsection{The baseline results}

We analyze the performance of pairs trading strategies for each industry, under the "persistence calibrated" standard deviation trigger. Risk and return characteristics are examined at the portfolio level. In addition to forming equal-weighted portfolios, we calculate buyand-hold portfolio returns, following Gatev et al. (2006). This approach takes into account compounded returns, known as value-weighted portfolio returns. The return computation under this approach is thus based on daily marked-to-market returns of individual pairs.

Table 2 reports estimated percentiles of trading trigger for each of the industry groups aggregated over the set of 30 rolling samples. Reported results demonstrate that there is error persistence delivering average trading triggers ranging from 0.65 to 0.98. Table 3 reports the excess return distribution by industry group and for the all-pair portfolio, representing all tradable targets, over the whole out-of-sample period since $2003 .{ }^{15}$ Panel A shows results from the equal-weighted portfolio, while Panel B presents profit estimates from the value-weighted portfolio. The general observation is that pairs portfolios gain statistically significant positive excess returns. We can see in Panel A that the equal-weighted portfolio generates an annualized average return of at least $4.33 \%$. Moreover only two portfolios earn mean returns lower than 5\%. Among the ten industries, pairs from Consumer Services deliver the highest average return equal to $7.72 \%$ per annum, followed by $7.46 \%$ earned in the Financials industry. Results therefore show clear positive performance which is consistent across different industries. We next look at the risk profile, measured by volatility. We can see that the first four industry portfolios (Financials, Industrials, Consumer Goods, and Consumer Services) show lower volatility and maximum return values than the remaining portfolios (Basic Materials, Utilities, Health Care, Technology, Telecommunications, and Oil \& Gas). This overall evidence indicates diversification benefits created from combining a

\footnotetext{
${ }^{15}$ Our strategy's profitability is induced from two positions. In this context the payoff is interpreted as excess return since trading profits or losses are earned from one euro investment in simultaneous long-short positions.
} 
larger number of pairs in a portfolio. This can be explained by the fact that the first four industries include more companies within the group. For this reason, they exhibit similar statistical properties. Reported results also demonstrate that the return distributions of industry portfolios are positively skewed, only with the exception of Health Care ${ }^{16}$. This implies that reported Sharpe ratio estimates may exhibit a downward bias. The finding of right-skewed distribution is consistent with Gatev et al. (2006) and Jurek and Yang (2007). However it is not supported by the work of Kondor (2009) arguing that arbitrageurs' total return is negatively skewed. Sharpe ratios are reported in the last column to evaluate the risk-adjusted portfolio performance. ${ }^{17}$ We find that half of these industry portfolios deliver a Sharpe ratio higher than 0.50. We contend that such impressive performance is clearly associated with the sector that gathers a larger number of companies. Our results therefore demonstrate that the proposed strategy is profitable for every industry categorized under STOXX Europe 600, and therefore the existence of positive profits is not industry dependent. The last row of Panel A (Table 3), examines the overall pairs trading performance taking together all pairs selected within industries, thus allowing investment on all tradable opportunities. The average annual return is close to $6.0 \%$ for this all-pair portfolio. More impressive is the annualized Sharpe ratio of 0.85 . This arises due to the large gains arising from diversification across pairs that trade in different industries as can be seen in the reported volatility of $6.81 \%$. In line with our findings from industry portfolios, cointegration delivers positively skewed portfolio returns.

We report in Panel $\mathrm{B}$ of Table 3 the results of value-weighted portfolios. Results are consistent with those presented in Panel A. Value-weighted portfolios however deliver higher Sharpe ratios and lower mean returns. The decrease in mean returns can also be found in Chen et al. (2012). The improvement in Sharpe ratio estimates is documented for most of industry portfolios as well as the all-pair portfolio. This arises as a consequence of lower return volatility. Value-weighted portfolios, are by construction less volatile than equal-

\footnotetext{
${ }^{16}$ The negative skew in the Health Care industry may be due to the high downside risk arising from high investment in R\&D.

${ }^{17}$ Simplified Sharpe ratios assume zero returns on the risk-free asset exploiting the fact that interest rates have been at historical minimum levels over our sample period. All Sharpe ratios reported in the paper are simplified under this assumption.
} 
weighted portfolios as weights in time $t$ are defined according to lagged returns. The all-pair portfolio earns on average an annual excess return of 3.35\%, and a Sharpe ratio of 1.03. The latter represents an improvement of $21 \%$ when compared to the equal-weighted all-pair portfolio. Note that this finding is consistent with the literature (See Plyakha et al. (2012) and Pae and Sabbaghi (2015)).

To unfold the economic significance from arbitrageurs' perspective, we consider the cumulative portfolio returns over our sample period. Figure 2 plots the cumulative profits on the equally weighted industry portfolios and the all-pair portfolio. These reinvested payoffs depict the evolution of an investor's wealth. It is observed that these portfolios earn cumulative profits of different magnitudes and, more interestingly, their returns exhibit various patterns. For instance, the industry portfolios, Consumer Goods and Consumer Services, accumulate wealth in a steady manner without considerable losses. Other sectors such as Financials and Utilities exhibit clearly pronounced rises over the 2008-2009 period. This evidence indicates that pairs belonging to distinct industries exhibit different response to market conditions leading to unresembling paths of return accumulation. However the common pattern across all portfolios is that there is a significant increase in profitability with the unfolding of the 2008 global financial crisis. This therefore suggests that our model-based pairs strategies can be used to hedge away market shocks and simultaneously yield significant profits under abnormal periods. This is consistent with the literature (see for example Alexander et al. (2002) and Do and Faff (2010)). The evolutionary path of wealth underlying the all-pair portfolio suggests that there is persistent profitability without the requirement of stop-loss criterion, over a 14-year period. This portfolio produces a total return of 0.86 at the end of the sample.

The baseline analysis above concludes that our pairs trading strategy is profitable. The robust performance confirms price convergence after the onset of a pricing anomaly, demonstrating while pricing errors are persistent, they eventually mean revert.

The next step is to introduce transaction costs and assess the impact on portfolio returns. Given that closing price data are used to compute abnormal returns, there is an identical 
probability of being at bid or ask. We impose corrections of these profits to reflect that, in practice, we long at the ask and sell at the bid prices. In other words, we have to subtract trading costs to get an estimate of profits net of transaction costs. To this end, we collect bid and ask prices for each equity pair. Because we long the loser and short the winner asset, transaction costs will reduce profits by one-half of the sum of the bid-ask spreads on both assets every time there is a change in position in the pair. Results reported in Table 3A reveal that, after accounting for transaction costs, Sharpe ratios and mean returns remain positive in all cases.

\subsection{Price discovery, relative turnover and portfolio replication}

Equations (13) -(14) show that price discovery is defined in terms of the relative number of participants in paired markets. Proxies for the relative number of participants can be found on relative liquidity measures. Another approach in the literature has been to address the relative number of analyst or informed traders following a given firm (see Brennan et al. (1993)). In this paper we follow FFG and use liquidity measures for this purpose. The relationship between price leadership and trading volume has been extensively addressed in the price discovery literature (see Hasbrouck (1995) and references therein). It has also been discussed in the asset pricing literature. Chordia and Swaminathan (2000) and Llorente et al. (2002) show that trading volumes deliver valuable information about future price movements and exerts impact on the speed of adjustment of individual stocks (see also Admati and Pfleiderer (1988)). The underlying presumption is that stocks that trade with higher liquidity respond faster to common information and become information leaders. Stocks that trade with low liquidity are therefore followers as they exhibit lower speed of price adjustment to common information. Variations in relative liquidity in both markets are therefore reflected on the changes in price discovery.

In what follows we check whether the result of price discovery in the theoretical model is confirmed empirically. We use for this purpose turnover as a proxy for market liquidity. 
Turnover is defined as the ratio of the number of shares traded in a day to the number of shares outstanding at the end of the day. Our interest is to see whether price leadership is associated with higher turnover. Specifically, we check for every pair screened out over each trading period, and calculate the percentage of them meeting the condition that the leader's average turnover is higher than the follower. Figure 3 shows the results. We can see that price leadership is associated with higher turnover for more than half of the pairs. This ratio is even higher for Financials (63\%), Industrials (64\%), Health Care (61\%), Telecommunications (61\%), and Oil \& Gas (64\%).

We now proceed to demonstrate the importance of price leadership determination for portfolio replication design. For this purpose, we repeat the trading exercise in Section 4.2 using the follower to replicate the leader. We denote these portfolios as "follower" portfolios. For comparison, Table 4 summarizes the excess returns for pairs portfolios which are present in Table 3. From Panel A we find that average returns of industry portfolios are lower compared to the baseline results. The same observation is applied to the performance metrics of Sharpe ratio. Comparing the all-pair portfolio return estimates under the equalweighted method, the baseline portfolio yields a mean return which is $1.42 \%$ higher than that reported for the "follower" portfolio. The baseline portfolio also outperforms its "follower" counterpart in terms of Sharpe ratio, which is 0.85 for the baseline and 0.74 for the "follower". These findings are robust to the use of value-based weights as reported in Panel B of Table 3 and 4 respectively.

Results therefore confirm that the theoretical implications on price leadership of the model exposed in Section 2 are important to maximize pairs trading profitability.

\subsection{A comparison of performance: Model-based trading algorithm versus GGR (2006)}

The purpose of this section is to compare the results of the proposed strategy with the results arising from the trading algorithm introduced by Gatev et al. (2006), acknowledged as the benchmark work in the pairs trading literature. GGR identify pairs by minimizing the sum of 
squared spreads between two normalized price series in a 1-year period. Although both GGR and our trading strategy exploit mean reversion in search of profitability, the seminal work of GGR is based on non-parametric past return correlation. Our strategy instead follows a model-based trading algorithm. To derive results under GGR methodology, we identify pairs within each of the ten industries and rank them by distance. In order to make the two trading algorithms comparable, we set the number of pairs included in an industry portfolio to be the same as the number of cointegrated pairs under our method, for every trading period. In other words, we guarantee that the portfolio size is identical under two different selection methods. The objective is to remove any diversification effects arising from sample size.

Following GGR, a trade is initiated if the prices diverge by more than two standard deviations. In Panel A of Table 5, we summarize the return performance delivered by GGR's equally weighted portfolios. Compared to the baseline results in Table 3, the mean portfolio return associated with our strategy is larger in all cases than that associated with GGR. The magnitude of return gap is between $1 \%$ and $3 \%$ per annum. On the basis of volatility, both strategies perform closely. In terms of the risk-return tradeoff, we find that our model-based industry portfolios yield Sharpe ratios that exceed GGR portfolios in seven out of ten cases. The magnitude of outperformance from our methodology is also significant. Furthermore, our all-pair portfolio, gains an annualized mean return which is $2.4 \%$ higher than that reported for GGR, and generates a Sharpe ratio of 0.85 , ten units higher than 0.75 achieved under GGR. Similar conclusions are reached when we compare on the basis of value-weighted portfolios.

Panel C in Table 5 shows results under GGR for alternative trading thresholds. Specifically we look at the profitability of the 1.5 and 3 standard deviations thresholds. It is clear that the alternative thresholds underperform the commonly used 2 standard deviations and therefore out proposed algorithm. Reported results therefore demonstrate that the combination of cointegration and a persistence-linked trading trigger proposed in this framework supersedes the benchmark methodology proposed in the literature. In order to evaluate the 
performance of our trading trigger solely, we have analyzed profitability under the 2 standard deviation case with selection performed under cointegration. Results, which can be provided upon request, demonstrate that our persistence-dependent trading trigger delivers significantly higher profitability than the 2 standard deviation trigger used as common benchmark in the literature.

\subsection{Commonality within industry groups: Firm Fundamental analysis}

The theoretical framework presented in Section 2 shows that two firms that share a common factor are linked via a long-run cointegration relationship. In our baseline empirical application, shared fundamentals arise due to commonalities at the industry, regulation and geographical levels. Common fundamentals arising from such restrictions give rise to stationary errors. In this section we filter our initial sample with firm specific fundamentals to identify stronger mean reversion reflected in less persistent mispricings and higher pairs trading profitability. We follow the asset pricing literature (see Fama and French (1993), Fama and French (1996), and Asness et al. (2013)) to consider a value factor measuring the long-run (or book) value relative to its current market value (BV/MV). We additionally control for the size effect using market capitalization and trading volume as proxy measures. In particular, we sort firms within a given industry, based on each of the factors (market cap, book-to-market ratio, and trading volume), and classify them into terciles. Then within each tercile, we identify a matching partner for every firm. Note that under this restriction, the number of selected pairs is much lower than that under the baseline study in Section 4.2. Given that firms are ranked into three groups, we are restricted to do this analysis on four industries for which the number of firms is more than 30: Financials, Industrials, Consumer Goods, and Consumer Services. Tables 6 and 7 present percentiles for coefficient estimations and pairs trading triggers. While coefficient estimations are highly consistent with the baseline estimation, the results show lower dispersion in the cointegration coefficient and higher speed of convergence due to the gain in commonality arising from firm-specific factor restrictions (note that simultaneous multi-factor restriction is not possible due to resulting low 
observations in each tercile portfolio). Table 8 displays the performance of equally-weighted portfolios for each of the factor restrictions. Results show that while the restriction on size does not provide a clear improvement, the book-to-market and volume restrictions clearly outperform the baseline case. Specifically, Panel B shows that in all industry portfolios the mean return is substantially larger under the book-to-market restriction. Such increase in magnitude counteracts with the resulting increase of volatility level. Accordingly, Sharpe ratios are superior to the baseline results. Finally Panel C reports the effect of trading volume on performance. Except from Consumer Services industry case, all analyzed portfolios deliver stronger performance in terms of mean return. They also yield higher Sharpe ratios relative to the baseline cases. The results of each tercile are available upon request.

The overall result suggests that the imposed additional restriction based on firm fundamentals, increases mean reversion and pairs trading performance. This is because of an improved identification of the common underlying factor. Reported results suggest superior performance under the book-to-market ratio and trading volume restrictions. This evidence can be attributed to the increased commonality shared between paired assets. Book-tomarket ratio and volume traded are therefore relevant proxies to firm fundamental values. Additional filtering of the initial sample on the basis of firm-level fundamentals implies stronger arbitrage forces between paired assets leading to higher stationarity and pairs trading profitability.

\section{Conclusion}

In this paper we adapt the demand and supply framework introduced by FFG to illustrate the process by which equities that share a common factor can be linked to exploit pairs trading opportunities. We derive market clearing conditions under a demand schedule including an arbitrage component and persistent cointegration errors. The dynamics of paired equity prices are represented via an economically meaningful VECM framework where convergence to the long-run relationship allows profits from pairs trading. Our model requires finite 
elasticity of demand for pairs trading strategies and exploits price discovery so that the leading asset can be used to replicate the follower. Pairs trading profitability is linked to the speed of mean reversion which is dependent on the elasticity of demand for pairs trading strategies and the total number of market participants. Based on this presumption, the presented framework derives a persistence-dependent trading threshold used to trigger pairs trading. In an extensive out-of-sample exercise applied to STOXX Europe 600 equity price daily data, we show that: (a) the use of price leadership for portfolio replication is important in determining profitability; (b) the proposed model-based pairs trading strategies yield positive Sharpe ratios that are higher than those obtained from competing pairs trading methodologies applied in the literature; (c) portfolio outperformance and mean reversion are enhanced under imposed firm fundamental factor as well as industry restrictions. 


\section{References}

Admati, A. R., Pfleiderer, P., 1988. A Theory of Intraday Patterns: Volume and Price Variability. Review of Financial Studies 1 (1), 3-40.

Alexander, C., Giblin, I., III, W. W., 2002. Cointegration and Asset Allocation: A New Active Hedge Fund Strategy. Research in International Business and Finance 16 (5), 65-90.

Andrade, S., Di Pietro, V., Seasholes, M., 2005. Understanding the Profitability of Pairs Trading. Working Paper, UC Berkeley, and Northwestern University.

Asness, C. S., Moskowitz, T. J., Pedersen, L. H., 2013. Value and Momentum Everywhere. The Journal of Finance 68 (3), 929-985.

Avellaneda, M., Lee, J., 2008. Statistical Arbitrage in the US Equities Market. Quantitative Finance $10(7), 761-782$.

Bowen, D. A., Hutchinson, M. C., 2014. Pairs Trading in the UK Equity Market: Risk and Return. The European Journal of Finance, 1-25.

Brennan, M. J., Jegadeesh, N., Swaminathan, B., 1993. Investment Analysis and the Adjustment of Stock Prices to Common Information. Review of Financial Studies 6 (4), 799-824.

Brennan, M. J., Schwartz, E. S., 1990. Arbitrage in Stock Index Futures. The Journal of Business 63 (1), S7-S31.

Broussard, J. P., Vaihekoski, M., 2012. Profitability of Pairs Trading Strategy in An Illiquid Market with Multiple Share Classes. Journal of International Financial Markets, Institutions and Money 22 (5), 1188-1201.

Chen, H., Chen, S., Li, F., 2012. Empirical Investigation of An Equity Pairs Trading Strategy. Working Paper, Texas A \& M University, University of British Columbia, and University of Michigan.

Chordia, T., Swaminathan, B., 2000. Trading Volume and Cross-autocorrelations in Stock Returns. The Journal of Finance 55 (2), 913-935. 
Do, B., Faff, R., 2010. Does Simple Pairs Trading Still Work? Financial Analysts Journal $66(4), 83-95$.

Elliott, R. J., Van Der Hoek, J., Malcolm, W. P., 2005. Pairs Trading. Quantitative Finance $5(3), 271-276$.

Fama, E. F., French, K. R., 1993. Common Risk Factors in the Returns on Stocks and Bonds. Journal of Financial Economics 33 (1), 3-56.

Fama, E. F., French, K. R., 1996. Multifactor Explanations of Asset Pricing Anomalies. The Journal of Finance 51 (1), 55-84.

Figuerola-Ferretti, I., Gonzalo, J., 2010. Modelling and Measuring Price Discovery in Commodity Markets. Journal of Econometrics 158 (1), 95-107.

Gatev, E., Goetzmann, W., Rouwenhorst, K., 2006. Pairs Trading: Performance of A Relative-Value Arbitrage Rule. Review of Financial Studies 19 (3), 797-827.

Gonzalo, J., Granger, C., 1995. Estimation of Common Long-Memory Components in Cointegrated Systems. Journal of Business \& Economic Statistics 13 (1), 27-35.

Gromb, D., Vayanos, D., 2002. Equilibrium and Welfare in Markets with Financially Constrained Arbitrageurs. Journal of Financial Economics 66 (2), 361-407.

Hasbrouck, J., 1995. One Security, Many Markets: Determining the Contributions to Price Discovery. The Journal of Finance 50 (4), 1175-1199.

Johansen, S., 1995. Likelihood-Based Inference in Cointegrated Vector Autoregressive Models. New York.

Jurek, J., Yang, H., 2007. Dynamic Portfolio Selection in Arbitrage. In: EFA 2006 Meetings Paper.

Juselius, K., 2006. The Cointegrated VAR Model: Methodology and Applications. Oxford University Press. 
Kanamura, T., Rachev, S. T., Fabozzi, F. J., 2010. A Profit Model for Spread Trading with an Application to Energy Futures. The Journal of Trading 5 (1), 48-62.

Kapadia, N., Pu, X., 2012. Limited Arbitrage between Equity and Credit Markets. Journal of Financial Economics 105 (3), 542-564.

Kondor, P., 2009. Risk in Dynamic Arbitrage: The Price Effects of Convergence Trading. The Journal of Finance 64 (2), 631-655.

Lehmann, B. N., 2002. Some Desiderata for the Measurement of Price Discovery Across Markets. Journal of Financial Markets 5 (3), 259-276.

Llorente, G., Michaely, R., Saar, G., Wang, J., 2002. Dynamic Volume-Return Relation of Individual Stocks. Review of Financial Studies 15 (4), 1005-1047.

McMillan, D. G., Ülkü, N., 2009. Persistent Mispricing in A Recently Opened Emerging Index Futures Market: Arbitrageurs Invited. Journal of Futures Markets 29 (3), 218-243.

Pae, Y., Sabbaghi, N., 2015. Equally Wweighted Portfolios vs Value Weighted Portfolios: Reasons for Differing Betas. Journal of Financial Stability 18, 203-207.

Park, T. H., Switzer, L. N., 1996. Mean Reversion of Interest-Rate Term Premiums and Profits from Trading Strategies with Treasury Futures Spreads. Journal of Futures Markets $16(3), 331-352$.

Plyakha, Y., Uppal, R., Vilkov, G., 2012. Why Does An Equal-weighted Portfolio Outperform Value- and Price-weighted Portfolios. Available at SSRN 1787045.

Schaefer, S. M., Strebulaev, I. A., 2008. Structural Models of Credit Risk are Useful: Evidence from Hedge Ratios on Corporate Bonds. Journal of Financial Economics 90 (1), $1-19$.

Shleifer, A., Vishny, R. W., 1997. The Limits of Arbitrage. The Journal of Finance 52 (1), $35-55$. 
Vidyamurthy, G., 2004. Pairs Trading: Quantitative Methods and Analysis. Vol. 217. John Wiley \& Sons.

Xiong, W., 2001. Convergence Trading with Wealth Effects: An Amplification Mechanism in Financial Markets. Journal of Financial Economics 62 (2), 247-292. 


\section{Appendix A.}

\section{A theoretical supply and demand model for pair trading dynamics}

Assume that a trader has identified two financial instruments whose prices $y_{t}$ and $x_{t}$ are cointegrated. The underlying long-term stationary relationship between both markets can be specified as:

$$
y_{t}=\gamma_{0}+\gamma_{1} x_{t}+z_{t}
$$

This implies that the value of asset $y_{t}$ can be replicated by a portfolio using asset $x_{t}$. Portfolio replication will be established on the basis of price leadership. $z_{t}$ represents the stationary arbitrage opportunities in two cointegrated markets arising from market imperfections. A trader exploits temporary mispricings from equilibrium by pursuing pairs trading strategies that short sell the outperforming asset and buy the underperformer. We con-

sider now the aggregate market demand function for all agents who perform pairs trading strategies taking simultaneous positions in $y_{t}$ and $x_{t}$ in period $t$. This is represented by:

$$
\begin{aligned}
H\left(\left(\gamma_{1} x_{t}+\gamma_{0}\right)-y_{t}\right) & , H & \succ 0 \\
=H\left(z_{t}\right) & , H & \succ 0
\end{aligned}
$$

where $H$ is the elasticity of demand for pairs trading strategies. It increases when transaction costs are negligible, and other market imperfections decrease as vehicles for crossmarket trading improve. In the limit, markets become perfectly integrated and the elasticity $H$ tends to infinity. When transaction costs are significant and there are market restrictions that impede inter-market trading, the elasticity of demand for pairs strategies is finite.

We assume that there are $N_{y}$ agents in the market for asset $y_{t}$ and $N_{x}$ agents in the market for asset $x_{t}$. These investors will take positions in asset $y_{t}$ and asset $x_{t}$ as well as pursue pairs trading in the two markets:

Let $Q_{i, t}$ be the number of shares owned by the $i^{t h}$ participant in period $t$ and $B_{i, t}$ the bid 
price at which that agent is willing to hold quantity $Q_{i, t}$. Then the demand function of the $i^{\text {th }}$ agent in the market for stock $y_{t}$ in period $t$ is

$$
Q_{i, t}-A\left(y_{t}-B_{i, t}\right)
$$

with $i=1, \ldots, N_{y}$ where $A \succ 0$, is the demand elasticity, assumed to be the same for all market agents.

The demand function for agent $j$ in the market for stock $x_{t}$ is

$$
Q_{j, t}-A\left(x_{t}-B_{j, t}\right), A \succ 0, j=1, \ldots, N_{x}
$$

The market for stock $y_{t}$ will clear at the value of $y_{t}$ that solves,

$$
\sum_{i=1}^{N_{y}} Q_{i, t}=\sum_{i=1}^{N_{y}}\left(Q_{i, t}-A\left(y_{t}-B_{i, t}\right)\right)+H\left(\left(\gamma_{1} x_{t}+\gamma_{0}\right)-y_{t}\right)
$$

with $H \succ 0$.

The market for stock $x_{t}$ will clear at the value of $x_{t}$ such that:

$$
\sum_{j=1}^{N_{x}} Q_{j, t}=\sum_{j=1}^{N_{x}}\left(Q_{j, t}-A\left(x_{t}-B_{j, t}\right)\right)+H\left(\left(\gamma_{1} x_{t}+\gamma_{0}\right)-y_{t}\right)
$$

Solving Equations (19) and (20) for $y_{t}$ and $x_{t}$ as a function of the mean bid price set by market agents in $y_{t}\left(B_{t}^{y}=N_{y}^{-1} \sum_{i=1}^{N_{y}} B_{i, t}\right)$ and the mean bid price $\left(B_{t}^{x}=N_{x}^{-1} \sum_{j=1}^{N_{x}} B_{j, t}\right)$ for market agents in $x_{t}$, we obtain:

$$
\begin{aligned}
& y_{t}=\frac{\left(A N_{x}+H \gamma_{1}\right) N_{y} B_{t}^{y}+H N_{x} \gamma_{1} B_{t}^{x}+H N_{x} \gamma_{0}}{\left(H+A N_{y}\right) N_{x}+H N_{y} \gamma_{1}} \\
& x_{t}=\frac{H N_{y} B_{t}^{y}+\left(A N_{y}+H\right) N_{x} B_{t}^{x}-H N_{y} \gamma_{0}}{\left(H+A N_{y}\right) N_{x}+H N_{y} \gamma_{1}}
\end{aligned}
$$


In what follows we derive the dynamic price relationships. This requires characterizing the model in Equation (21) with a description of the evolution of bid prices. It is assumed that immediately after the market clearing period $t-1$ the $i^{\text {th }}$ agent in $y_{t}$ was willing to hold a position of $Q_{i, t}$ at a price $y_{t-1}$. Following FFG, this implies that $y_{t-1}$ was his bid price after that clearing. We assume that this bid price changes to $B_{i, t}$ according to the equation

$$
\begin{gathered}
B_{i, t}=y_{t-1}+e_{t}+w_{i, t} \\
B_{j, t}=x_{t-1}+e_{t}+w_{j, t} \\
\operatorname{cov}\left(e_{t}, w_{i, t}\right)=\quad 0, \forall i \\
\operatorname{cov}\left(w_{i, t}, w_{j, t}\right)=0, \forall i \neq j
\end{gathered}
$$

with $i=1, \ldots, N_{y}$ and $j=1, \ldots, N_{x}$. Where the vector $\left(e_{t}, w_{i, t}, w_{j, t}\right)$ is vector white noise with finite variance.

The price change $B_{i, t}-y_{t-1}$ reflects the arrival of new information between period $t-1$ and period $t$ which changes the price at which the $i^{\text {th }}$ participant is willing to hold a position of $Q_{i, t}$ in the market $y_{t}$. This price change has a component common to all market agents $\left(e_{t}\right)$ and a component idiosyncratic to the $i^{t h}$ agent $\left(w_{i, t}\right)$.

The equations in (22) imply that the mean bid price in each market in period $t$ will be

$$
\begin{aligned}
& B_{t}^{y}=y_{t-1}+e_{t}+w_{t}^{y} \\
& B_{t}^{x}=x_{t-1}+e_{t}+w_{t}^{x}
\end{aligned}
$$

where $w_{t}^{y}=\frac{\sum_{i=1}^{N_{y}} w_{i, t}^{y}}{N_{y}}$ and $w_{t}^{x}=\frac{\sum_{j=1}^{N_{x}} w_{j, t}^{x}}{N_{x}}$. Substituting expressions (23) into (21) yields the following vector model:

$$
\left(\begin{array}{l}
y_{t} \\
x_{t}
\end{array}\right)=\frac{H \gamma_{0}}{d}\left(\begin{array}{c}
N_{x} \\
-N_{y}
\end{array}\right)+M\left(\begin{array}{l}
y_{t-1} \\
x_{t-1}
\end{array}\right)+\left(\begin{array}{c}
u_{t}^{y} \\
u_{t}^{x}
\end{array}\right)
$$


where

$$
\begin{gathered}
\left(\begin{array}{c}
u_{t}^{y} \\
u_{t}^{x}
\end{array}\right)=M\left(\begin{array}{c}
e_{t}+w_{t}^{y} \\
e_{t}+w_{t}^{x}
\end{array}\right) \\
M=\frac{1}{d}\left[\begin{array}{cc}
N_{y}\left(\gamma_{1} H+A N_{x}\right) & \gamma_{1} H N_{x} \\
H N_{y} & \left(H+A N_{y}\right) N_{x}
\end{array}\right]
\end{gathered}
$$

And

$$
d=\left(H+A N_{y}\right) N_{x}+\gamma_{1} H N_{y}
$$

We next convert Equation (24) into a Vector Error Correction Model (VECM) by subtracting $\left(y_{t-1}, x_{t-1}\right)^{\prime}$ from both sides, with

$$
\begin{gathered}
\left(\begin{array}{c}
\Delta y_{t} \\
\Delta x_{t}
\end{array}\right)=\frac{H \gamma_{0}}{d}\left(\begin{array}{c}
N_{x} \\
-N_{y}
\end{array}\right)+(M-I)\left(\begin{array}{c}
y_{t-1} \\
x_{t-1}
\end{array}\right)+\left(\begin{array}{c}
u_{t}^{y} \\
u_{t}^{x}
\end{array}\right) \\
M-I=\frac{1}{d}\left[\begin{array}{cc}
-H N_{x} & \gamma_{1} H N_{x} \\
H N_{y} & -H N_{y} \gamma_{1}
\end{array}\right]
\end{gathered}
$$

Rearranging terms,

$$
\left(\begin{array}{c}
\Delta y_{t} \\
\Delta x_{t}
\end{array}\right)=\frac{H}{d}\left(\begin{array}{c}
-N_{x} \\
N_{y}
\end{array}\right)\left(\begin{array}{lll}
1 & -\gamma_{1} & -\gamma_{0}
\end{array}\right)\left(\begin{array}{c}
y_{t-1} \\
x_{t-1} \\
1
\end{array}\right)+\left(\begin{array}{c}
u_{t}^{y} \\
u_{t}^{x}
\end{array}\right)
$$




\section{Appendix B. Empirical Results}

Table 1: Estimation of VECM parameters

\begin{tabular}{|c|c|c|c|c|c|c|}
\hline \multicolumn{2}{|l|}{ Sample } & 5th Percentile & 25th Percentile & Median & 75th Percentile & 95th Percentile \\
\hline \multicolumn{7}{|c|}{ Panel A: Estimated values of $\alpha_{1}$ and $\alpha_{2}$} \\
\hline \multirow[t]{2}{*}{ Financials } & $\alpha_{1}$ & -0.013 & -0.036 & -0.076 & -0.150 & -0.302 \\
\hline & $\alpha_{2}$ & 0.001 & 0.005 & 0.012 & 0.029 & 0.076 \\
\hline \multirow[t]{2}{*}{ Industrials } & $\alpha_{1}$ & -0.020 & -0.038 & -0.066 & -0.112 & -0.323 \\
\hline & $\alpha_{2}$ & 0.001 & 0.007 & 0.015 & 0.028 & 0.058 \\
\hline \multirow[t]{2}{*}{ Consumer Goods } & $\alpha_{1}$ & -0.021 & -0.052 & -0.090 & -0.136 & -0.201 \\
\hline & $\alpha_{2}$ & 0.002 & 0.008 & 0.018 & 0.036 & 0.077 \\
\hline \multirow[t]{2}{*}{ Consumer Services } & $\alpha_{1}$ & -0.017 & -0.036 & -0.063 & -0.115 & -0.254 \\
\hline & $\alpha_{2}$ & 0.002 & 0.006 & 0.013 & 0.024 & 0.052 \\
\hline \multirow[t]{2}{*}{ Basic Materials } & $\alpha_{1}$ & -0.040 & -0.059 & -0.082 & -0.112 & -0.170 \\
\hline & $\alpha_{2}$ & 0.004 & 0.012 & 0.024 & 0.041 & 0.064 \\
\hline \multirow[t]{2}{*}{ Utilities } & $\alpha_{1}$ & -0.009 & -0.014 & -0.028 & -0.048 & -0.089 \\
\hline & $\alpha_{2}$ & 0.001 & 0.002 & 0.005 & 0.009 & 0.023 \\
\hline \multirow[t]{2}{*}{ Health Care } & $\alpha_{1}$ & -0.046 & -0.060 & -0.087 & -0.125 & -0.200 \\
\hline & $\alpha_{2}$ & 0.004 & 0.010 & 0.018 & 0.032 & 0.052 \\
\hline \multirow[t]{2}{*}{ Technology } & $\alpha_{1}$ & -0.035 & -0.046 & -0.067 & -0.092 & -0.147 \\
\hline & $\alpha_{2}$ & 0.005 & 0.010 & 0.020 & 0.032 & 0.052 \\
\hline \multirow[t]{2}{*}{ Telecommunications } & $\alpha_{1}$ & -0.011 & -0.017 & -0.028 & -0.038 & -0.059 \\
\hline & $\alpha_{2}$ & 0.002 & 0.004 & 0.008 & 0.015 & 0.023 \\
\hline \multirow[t]{2}{*}{ Oil \& Gas } & $\alpha_{1}$ & -0.026 & -0.038 & -0.053 & -0.070 & -0.090 \\
\hline & $\alpha_{2}$ & 0.002 & 0.004 & 0.011 & 0.020 & 0.031 \\
\hline \multicolumn{7}{|c|}{ Panel B: Estimated values of $\gamma_{1}$} \\
\hline Financials & & 0.14 & 0.45 & 1.43 & 7.06 & 11.64 \\
\hline Industrials & & 0.14 & 0.42 & 0.94 & 2.76 & 10.65 \\
\hline Consumer Goods & & 0.26 & 0.58 & 1.30 & 2.88 & 7.99 \\
\hline Consumer Services & & 0.28 & 0.49 & 0.88 & 1.95 & 4.96 \\
\hline Basic Materials & & 0.32 & 0.46 & 0.96 & 1.83 & 3.33 \\
\hline Utilities & & 0.23 & 0.45 & 0.93 & 3.34 & 9.86 \\
\hline Health Care & & 1.07 & 1.27 & 1.79 & 2.76 & 4.07 \\
\hline Technology & & 0.54 & 0.76 & 1.15 & 1.99 & 5.15 \\
\hline Telecommunications & & 2.17 & 2.25 & 2.62 & 4.25 & 6.60 \\
\hline Oil \& Gas & & 0.64 & 0.80 & 1.10 & 2.49 & 3.99 \\
\hline
\end{tabular}

This table presents the values of $\alpha_{1}$ and $\alpha_{2}$ obtained using the Johansen cointegration methodology in Panel A. The percentiles for $\alpha_{1}$ are computed using the absolute values. Summary statistics of estimated values of $\gamma_{1}$ are reported in Panel B. As the Johansen test is conducted on a rolling-window basis, these reported values are an average value computed from a series of estimates of each percentile. The sample period is January 2000 to February 6 th 2017. 
Table 2: Model-derived trading trigger $1+\alpha_{1}-\gamma_{1} \alpha_{2}$

\begin{tabular}{lccccc}
\hline Sample & 5th Percentile & 25th Percentile & Median & 75th Percentile & 95th Percentile \\
\hline Financials & 0.65 & 0.80 & 0.89 & 0.93 & 0.97 \\
Industrials & 0.80 & 0.87 & 0.91 & 0.93 & 0.98 \\
Consumer Goods & 0.79 & 0.84 & 0.89 & 0.93 & 0.97 \\
Consumer Services & 0.81 & 0.86 & 0.91 & 0.94 & 0.96 \\
Basic Materials & 0.83 & 0.85 & 0.88 & 0.90 & 0.92 \\
Utilities & 0.90 & 0.91 & 0.94 & 0.95 & 0.96 \\
Health Care & 0.83 & 0.84 & 0.86 & 0.88 & 0.90 \\
Technology & 0.84 & 0.87 & 0.90 & 0.92 & 0.97 \\
Telecommunications & 0.89 & 0.93 & 0.94 & 0.97 & 0.98 \\
Oil \& Gas & 0.88 & 0.90 & 0.91 & 0.93 & 0.94 \\
\hline
\end{tabular}

This table presents the values of model-derived trading trigger $1+\alpha_{1}-\gamma_{1} \alpha_{2}$, which is computed using VECM estimates obtained from the Johansen cointegration methodology. As the trading strategy is conducted on a rolling-window basis, these reported values are an average value computed from a series of threshold numbers of each percentile. The sample period is January 2000 to February 6th 2017. 
Table 3: Summary statistics of excess returns to pairs portfolios

\begin{tabular}{|c|c|c|c|c|c|c|c|c|}
\hline Sample & Mean & Median & Stdev & Skew & Kurtosis & Max. & Min. & Sharpe \\
\hline \multicolumn{9}{|c|}{ Panel A: Equal-weighted portfolios } \\
\hline Financials & 0.0746 & 0.0000 & 0.1467 & 0.57 & 14.44 & 0.07 & -0.07 & 0.51 \\
\hline Industrials & 0.0433 & 0.0000 & 0.1318 & 0.15 & 10.76 & 0.07 & -0.07 & 0.33 \\
\hline Consumer Goods & 0.0514 & 0.0000 & 0.0943 & 0.69 & 17.45 & 0.06 & -0.05 & 0.54 \\
\hline Consumer Services & 0.0772 & 0.0000 & 0.1235 & 0.48 & 14.17 & 0.09 & -0.06 & 0.63 \\
\hline Basic Materials & 0.0662 & 0.0000 & 0.1642 & 0.08 & 18.54 & 0.09 & -0.14 & 0.40 \\
\hline Utilities & 0.0553 & 0.0000 & 0.1585 & 1.40 & 29.37 & 0.14 & -0.10 & 0.35 \\
\hline Health Care & 0.0644 & 0.0000 & 0.1163 & -1.60 & 43.23 & 0.05 & -0.14 & 0.55 \\
\hline Technology & 0.0587 & 0.0000 & 0.1728 & 0.67 & 13.63 & 0.12 & -0.07 & 0.34 \\
\hline Telecommunications & 0.0470 & 0.0000 & 0.1735 & 1.08 & 22.32 & 0.14 & -0.08 & 0.27 \\
\hline Oil \& Gas & 0.0579 & 0.0000 & 0.1034 & 0.94 & 18.12 & 0.07 & -0.05 & 0.56 \\
\hline All-Pair Portfolio & 0.0576 & 0.0154 & 0.0681 & 0.89 & 14.25 & 0.04 & -0.03 & 0.85 \\
\hline \multicolumn{9}{|c|}{ Panel B: Value-weighted portfolios } \\
\hline Financials & 0.0506 & 0.0000 & 0.0700 & 0.62 & 16.38 & 0.03 & -0.04 & 0.72 \\
\hline Industrials & 0.0246 & 0.0000 & 0.0639 & 0.26 & 10.47 & 0.03 & -0.03 & 0.38 \\
\hline Consumer Goods & 0.0272 & 0.0000 & 0.0454 & 0.73 & 15.61 & 0.03 & -0.02 & 0.60 \\
\hline Consumer Services & 0.0467 & 0.0000 & 0.0613 & 0.56 & 16.20 & 0.04 & -0.03 & 0.76 \\
\hline Basic Materials & 0.0346 & 0.0000 & 0.0808 & 0.26 & 18.06 & 0.05 & -0.06 & 0.43 \\
\hline Utilities & 0.0292 & 0.0000 & 0.0796 & 1.88 & 38.70 & 0.08 & -0.05 & 0.37 \\
\hline Health Care & 0.0455 & 0.0000 & 0.0960 & -0.12 & 11.83 & 0.05 & -0.06 & 0.48 \\
\hline Technology & 0.0303 & 0.0000 & 0.0849 & 0.62 & 13.17 & 0.06 & -0.03 & 0.36 \\
\hline Telecommunications & 0.0313 & 0.0000 & 0.0967 & 1.06 & 23.31 & 0.06 & -0.06 & 0.32 \\
\hline Oil \& Gas & 0.0309 & 0.0000 & 0.0504 & 1.03 & 18.11 & 0.03 & -0.02 & 0.61 \\
\hline All-Pair Portfolio & 0.0335 & 0.0051 & 0.0326 & 0.90 & 12.78 & 0.02 & -0.01 & 1.03 \\
\hline
\end{tabular}

This table presents descriptive statistics of excess returns for each industry group and the all-pair portfolio. We trade according to the rule that opens a position in a pair one day after price spread diverges more than $\left(1+\alpha_{1}-\gamma_{1} \alpha_{2}\right)$ units of historical standard deviation. Reported are the mean and median excess return (annualized), the (annualized) standard deviation, skew, kurtosis, the maximum and minimum daily excess return and (annualized) Sharpe ratio. The sample period is January 2000 to February 6th 2017. 
Table 3A: Summary statistics of excess returns to pairs portfolios after transaction costs

\begin{tabular}{lcccccccc}
\hline Sample & Mean & Median & Stdev & Skew & Kurtosis & Max. & Min. & Sharpe \\
\hline Financials & 0.0325 & 0.0000 & 0.0901 & 0.83 & 20.76 & 0.06 & -0.05 & 0.36 \\
Industrials & 0.0157 & 0.0000 & 0.0834 & 0.80 & 22.25 & 0.07 & -0.05 & 0.19 \\
Consumer Goods & 0.0314 & 0.0000 & 0.0942 & 0.69 & 17.56 & 0.06 & -0.05 & 0.33 \\
Consumer Services & 0.0618 & 0.0000 & 0.1228 & 0.48 & 14.48 & 0.09 & -0.06 & 0.50 \\
Basic Materials & 0.0470 & 0.0000 & 0.1643 & 0.07 & 18.49 & 0.09 & -0.14 & 0.29 \\
Utilities & 0.0395 & 0.0000 & 0.1532 & 1.09 & 22.86 & 0.08 & -0.05 & 0.27 \\
Health Care & 0.0428 & 0.0000 & 0.1163 & -1.60 & 43.24 & 0.05 & -0.14 & 0.37 \\
Technology & 0.0472 & 0.0000 & 0.1727 & 0.68 & 13.68 & 0.12 & -0.07 & 0.27 \\
Telecommunications & 0.0282 & 0.0000 & 0.1299 & 1.35 & 26.32 & 0.10 & -0.06 & 0.22 \\
Oil \& Gas & 0.0487 & 0.0000 & 0.1054 & 0.62 & 19.31 & 0.07 & -0.06 & 0.46 \\
All-Pair Portfolio & 0.0356 & 0.0000 & 0.0674 & 0.94 & 14.77 & 0.04 & -0.03 & 0.53 \\
\hline
\end{tabular}

This table presents descriptive statistics of excess returns net of transaction costs, for each industry group and the all-pair portfolio. Transaction costs are estimated as one-half of the sum of the bid-ask spreads on both assets. Reported are the mean and median excess return (annualized), the (annualized) standard deviation, skew, kurtosis, the maximum and minimum daily excess return and (annualized) Sharpe ratio. The sample period is January 2000 to February 6th 2017. 
Table 4: Excess returns to alternative pairs trading: the switch of leadership

\begin{tabular}{|c|c|c|c|c|c|c|c|c|}
\hline Sample & Mean & Median & Stdev & Skew & Kurtosis & Max. & Min. & Sharpe \\
\hline \multicolumn{9}{|c|}{ Panel A: Equal-weighted portfolios } \\
\hline Financials & 0.0533 & 0.0000 & 0.1395 & 1.09 & 19.12 & 0.09 & -0.08 & 0.38 \\
\hline Industrials & 0.0404 & 0.0000 & 0.1530 & -0.36 & 18.89 & 0.08 & -0.11 & 0.26 \\
\hline Consumer Goods & 0.0443 & 0.0287 & 0.1182 & -0.90 & 22.70 & 0.06 & -0.11 & 0.37 \\
\hline Consumer Services & 0.0575 & 0.0000 & 0.1055 & 0.46 & 10.28 & 0.05 & -0.05 & 0.55 \\
\hline Basic Materials & 0.0288 & 0.0000 & 0.1618 & -0.28 & 19.74 & 0.09 & -0.14 & 0.18 \\
\hline Utilities & 0.0466 & 0.0000 & 0.1137 & 0.60 & 19.90 & 0.08 & -0.07 & 0.41 \\
\hline Health Care & 0.0511 & 0.0000 & 0.1306 & 0.07 & 20.70 & 0.08 & -0.11 & 0.39 \\
\hline Technology & 0.0276 & 0.0000 & 0.1509 & 0.40 & 12.91 & 0.07 & -0.07 & 0.18 \\
\hline Telecommunications & 0.0331 & 0.0000 & 0.1440 & 0.66 & 20.82 & 0.09 & -0.07 & 0.23 \\
\hline Oil \& Gas & 0.0405 & 0.0000 & 0.1579 & -0.25 & 14.72 & 0.09 & -0.08 & 0.26 \\
\hline All-Pair Portfolio & 0.0435 & 0.0000 & 0.0585 & 0.40 & 12.00 & 0.03 & -0.02 & 0.74 \\
\hline \multicolumn{9}{|c|}{ Panel B: Value-weighted portfolios } \\
\hline Financials & 0.0401 & 0.0000 & 0.0635 & 1.30 & 17.28 & 0.04 & -0.03 & 0.63 \\
\hline Industrials & 0.0230 & 0.0000 & 0.0737 & -0.12 & 16.66 & 0.04 & -0.05 & 0.31 \\
\hline Consumer Goods & 0.0333 & 0.0117 & 0.0579 & -0.41 & 18.23 & 0.03 & -0.05 & 0.58 \\
\hline Consumer Services & 0.0332 & 0.0000 & 0.0509 & 0.64 & 9.44 & 0.03 & -0.02 & 0.65 \\
\hline Basic Materials & 0.0141 & 0.0000 & 0.0809 & -0.13 & 18.06 & 0.05 & -0.07 & 0.17 \\
\hline Utilities & 0.0264 & 0.0000 & 0.0574 & 0.83 & 21.64 & 0.04 & -0.03 & 0.46 \\
\hline Health Care & 0.0244 & 0.0000 & 0.0655 & 0.24 & 16.95 & 0.04 & -0.05 & 0.37 \\
\hline Technology & 0.0209 & 0.0000 & 0.0781 & 0.62 & 14.87 & 0.04 & -0.03 & 0.27 \\
\hline Telecommunications & 0.0211 & 0.0000 & 0.0719 & 0.73 & 19.90 & 0.04 & -0.04 & 0.29 \\
\hline Oil \& Gas & 0.0200 & 0.0000 & 0.0787 & -0.32 & 14.47 & 0.04 & -0.04 & 0.25 \\
\hline All-Pair Portfolio & 0.0253 & 0.0013 & 0.0278 & 0.79 & 9.24 & 0.01 & -0.01 & 0.91 \\
\hline
\end{tabular}

This table presents descriptive statistics of excess returns for each industry group and the all-pair portfolio. We trade according to the rule that opens a position in a pair one day after price spread diverges more than $\left(1+\alpha_{1}-\gamma_{1} \alpha_{2}\right)$ units of historical standard deviation. Contrary to portfolios in Table 3, the leadership is switched when establishing pairs portfolios. That is, we use the price of follower to replicate the leader in this alternative trading rule. Reported are the mean and median excess return (annualized), the (annualized) standard deviation, skew, kurtosis, the maximum and minimum daily excess return and (annualized) Sharpe ratio. The sample period is January 2000 to February 6 th 2017. 
Table 5: Summary statistics of excess returns to GGR portfolios

\begin{tabular}{|c|c|c|c|c|c|c|c|c|}
\hline Sample & Mean & Median & Stdev & Skew & Kurtosis & Max. & Min. & Sharpe \\
\hline \multicolumn{9}{|c|}{ Panel A: Equal-weighted portfolios } \\
\hline Financials & 0.0685 & 0.0000 & 0.1854 & 0.43 & 11.14 & 0.12 & -0.12 & 0.37 \\
\hline Industrials & 0.0324 & 0.0000 & 0.0870 & 0.80 & 45.21 & 0.06 & -0.05 & 0.37 \\
\hline Consumer Goods & 0.0313 & 0.0000 & 0.0533 & 1.59 & 25.52 & 0.04 & -0.02 & 0.59 \\
\hline Consumer Services & 0.0688 & 0.0000 & 0.1430 & 2.22 & 40.89 & 0.22 & -0.14 & 0.48 \\
\hline Basic Materials & 0.0167 & 0.0000 & 0.0837 & -0.82 & 28.88 & 0.09 & -0.17 & 0.20 \\
\hline Utilities & 0.0326 & 0.0000 & 0.0872 & 1.84 & 31.66 & 0.06 & -0.04 & 0.37 \\
\hline Health Care & 0.0461 & 0.0000 & 0.1017 & 0.21 & 54.89 & 0.09 & -0.09 & 0.45 \\
\hline Technology & 0.0403 & 0.0000 & 0.1797 & 1.79 & 27.40 & 0.13 & -0.09 & 0.22 \\
\hline Telecommunications & 0.0359 & 0.0000 & 0.1941 & 1.23 & 26.63 & 0.13 & -0.12 & 0.19 \\
\hline Oil \& Gas & 0.0262 & 0.0000 & 0.0971 & 1.35 & 34.28 & 0.11 & -0.07 & 0.27 \\
\hline All-Pair Portfolio & 0.0335 & 0.0000 & 0.0445 & 1.83 & 27.95 & 0.03 & -0.02 & 0.75 \\
\hline \multicolumn{9}{|c|}{ Panel B: Value-weighted portfolios } \\
\hline Financials & 0.0415 & 0.0000 & 0.1021 & 0.06 & 29.57 & 0.10 & -0.11 & 0.33 \\
\hline Industrials & 0.0188 & 0.0000 & 0.0402 & 0.81 & 47.47 & 0.03 & -0.02 & 0.62 \\
\hline Consumer Goods & 0.0151 & 0.0000 & 0.0286 & 1.50 & 24.06 & 0.02 & -0.01 & 0.81 \\
\hline Consumer Services & 0.0387 & 0.0000 & 0.0790 & 2.25 & 37.90 & 0.11 & -0.06 & 0.35 \\
\hline Basic Materials & 0.0061 & 0.0000 & 0.0828 & -0.87 & 28.83 & 0.04 & -0.08 & 0.07 \\
\hline Utilities & 0.0194 & 0.0000 & 0.0434 & 2.11 & 33.87 & 0.03 & -0.02 & 0.45 \\
\hline Health Care & 0.0567 & 0.0000 & 0.0805 & 0.57 & 22.22 & 0.06 & -0.06 & 0.71 \\
\hline Technology & 0.0158 & 0.0000 & 0.0918 & 1.84 & 29.36 & 0.07 & -0.05 & 0.17 \\
\hline Telecommunications & 0.0264 & 0.0000 & 0.1037 & 1.99 & 32.23 & 0.08 & -0.05 & 0.25 \\
\hline Oil \& Gas & 0.0128 & 0.0000 & 0.0513 & 1.24 & 34.24 & 0.06 & -0.04 & 0.20 \\
\hline All-Pair Portfolio & 0.0206 & 0.0000 & 0.0249 & 1.69 & 21.80 & 0.01 & -0.01 & 0.83 \\
\hline \multicolumn{9}{|c|}{ Panel C: Equal-weighted all-pair portfolios at two different thresholds } \\
\hline 1.5 standard deviations & 0.0313 & 0.0000 & 0.0463 & 1.71 & 25.50 & 0.03 & -0.02 & 0.68 \\
\hline 3 standard deviations & 0.0173 & 0.0000 & 0.0386 & 1.54 & 38.96 & 0.03 & -0.02 & 0.45 \\
\hline
\end{tabular}

This table presents statistics of excess returns for industry groups and the all-pair portfolio under GGR. We trade based on the rule that opens a position in a pair one day after price spread diverges over 2 standard deviations in Panel A and B, while the same rule is applied but subject to 1.5 and 3 standard deviations in Panel C. Reported are the mean and median excess return (annualized), the (annualized) standard deviation, skew, kurtosis, the maximum and minimum daily excess return and (annualized) Sharpe ratio. The sample period is Jan. 2000 to Feb. 6th 2017. 
Table 6: VECM estimates and the model-derived trading trigger for pairs controlling book-to-market ratio

\begin{tabular}{|c|c|c|c|c|c|c|}
\hline Sample & & 5th Percentile & 25th Percentile & Median & 75th Percentile & 95th Percentile \\
\hline \multicolumn{7}{|c|}{ Panel A: Estimated values of $\alpha_{1}$ and $\alpha_{2}$} \\
\hline \multirow[t]{2}{*}{ Financials } & $\alpha_{1}$ & -0.013 & -0.041 & -0.079 & -0.146 & -0.306 \\
\hline & $\alpha_{2}$ & 0.001 & 0.005 & 0.014 & 0.030 & 0.076 \\
\hline \multirow[t]{2}{*}{ Industrials } & $\alpha_{1}$ & -0.023 & -0.039 & -0.067 & -0.120 & -0.312 \\
\hline & $\alpha_{2}$ & 0.002 & 0.008 & 0.016 & 0.029 & 0.064 \\
\hline \multirow[t]{2}{*}{ Consumer Goods } & $\alpha_{1}$ & -0.023 & -0.047 & -0.090 & -0.142 & -0.200 \\
\hline & $\alpha_{2}$ & 0.003 & 0.009 & 0.017 & 0.034 & 0.067 \\
\hline \multirow[t]{2}{*}{ Consumer Services } & $\alpha_{1}$ & -0.037 & -0.052 & -0.077 & -0.122 & -0.260 \\
\hline & $\alpha_{2}$ & 0.006 & 0.009 & 0.016 & 0.026 & 0.052 \\
\hline \multicolumn{7}{|c|}{ Panel B: Estimated values of $\gamma_{1}$} \\
\hline Financials & & 0.18 & 0.45 & 1.35 & 4.58 & 7.92 \\
\hline Industrials & & 0.19 & 0.45 & 0.94 & 2.68 & 10.08 \\
\hline Consumer Goods & & 0.40 & 0.74 & 1.54 & 2.96 & 7.03 \\
\hline Consumer Services & & 0.55 & 0.70 & 0.98 & 1.66 & 3.19 \\
\hline \multicolumn{7}{|c|}{ Panel C: Model-derived trading trigger $1+\alpha_{1}-\gamma_{1} \alpha_{2}$} \\
\hline Financials & & 0.63 & 0.80 & 0.88 & 0.93 & 0.96 \\
\hline Industrials & & 0.79 & 0.86 & 0.91 & 0.94 & 0.96 \\
\hline Consumer Goods & & 0.80 & 0.83 & 0.88 & 0.94 & 0.98 \\
\hline Consumer Services & & 0.80 & 0.86 & 0.91 & 0.93 & 0.96 \\
\hline
\end{tabular}

This table presents the values of $\alpha_{1}$ and $\alpha_{2}$ obtained using the Johansen cointegration methodology in Panel A. The percentiles for $\alpha_{1}$ are computed using the absolute values. Summary statistics of estimated values of $\gamma_{1}$ are reported in Panel B. Panel C presents the values of model-derived trading trigger $1+\alpha_{1}-\gamma_{1} \alpha_{2}$, which is computed using the resulting VECM estimates. As the Johansen estimation and the following trading activities are conducted on a rolling-window basis, these reported values are an average value computed from a series of numbers of each percentile. The sample period is January 2000 to February 6th 2017. 
Table 7: VECM estimates and the model-derived trading trigger for pairs controlling trading volume

\begin{tabular}{|c|c|c|c|c|c|c|}
\hline Sample & & 5th Percentile & 25th Percentile & Median & 75th Percentile & 95th Percentile \\
\hline \multicolumn{7}{|c|}{ Panel A: Estimated values of $\alpha_{1}$ and $\alpha_{2}$} \\
\hline \multirow[t]{2}{*}{ Financials } & $\alpha_{1}$ & -0.012 & -0.036 & -0.078 & -0.152 & -0.294 \\
\hline & $\alpha_{2}$ & 0.001 & 0.004 & 0.012 & 0.029 & 0.077 \\
\hline \multirow[t]{2}{*}{ Industrials } & $\alpha_{1}$ & -0.021 & -0.037 & -0.063 & -0.121 & -0.252 \\
\hline & $\alpha_{2}$ & 0.002 & 0.007 & 0.014 & 0.026 & 0.054 \\
\hline \multirow[t]{2}{*}{ Consumer Goods } & $\alpha_{1}$ & -0.030 & -0.061 & -0.091 & -0.134 & -0.189 \\
\hline & $\alpha_{2}$ & 0.005 & 0.009 & 0.020 & 0.038 & 0.068 \\
\hline \multirow[t]{2}{*}{ Consumer Services } & $\alpha_{1}$ & -0.027 & -0.039 & -0.066 & -0.090 & -0.136 \\
\hline & $\alpha_{2}$ & 0.006 & 0.008 & 0.015 & 0.022 & 0.036 \\
\hline \multicolumn{7}{|c|}{ Panel B: Estimated values of $\gamma_{1}$} \\
\hline Financials & & 0.14 & 0.48 & 1.48 & 6.84 & 9.84 \\
\hline Industrials & & 0.20 & 0.43 & 0.89 & 2.92 & 10.67 \\
\hline Consumer Goods & & 0.37 & 0.82 & 1.69 & 3.27 & 7.87 \\
\hline Consumer Services & & 0.35 & 0.48 & 0.82 & 1.64 & 3.06 \\
\hline \multicolumn{7}{|c|}{ Panel C: Model-derived trading trigger $1+\alpha_{1}-\gamma_{1} \alpha_{2}$} \\
\hline Financials & & 0.65 & 0.80 & 0.89 & 0.93 & 0.97 \\
\hline Industrials & & 0.81 & 0.87 & 0.91 & 0.93 & 0.96 \\
\hline Consumer Goods & & 0.79 & 0.83 & 0.88 & 0.92 & 0.95 \\
\hline Consumer Services & & 0.81 & 0.87 & 0.91 & 0.94 & 0.96 \\
\hline
\end{tabular}

This table presents the values of $\alpha_{1}$ and $\alpha_{2}$ obtained using the Johansen cointegration methodology in Panel A. The percentiles for $\alpha_{1}$ are computed using the absolute values. Summary statistics of estimated values of $\gamma_{1}$ are reported in Panel B. Panel C presents the values of model-derived trading trigger $1+\alpha_{1}-\gamma_{1} \alpha_{2}$, which is computed using the resulting VECM estimates. As the Johansen estimation and the following trading activities are conducted on a rolling-window basis, these reported values are an average value computed from a series of numbers of each percentile. The sample period is January 2000 to February 6th 2017. 
Table 8: Summary statistics of excess returns to equal-weighted pairs portfolios controlling common factors

\begin{tabular}{|c|c|c|c|c|c|c|c|c|}
\hline Sample & Mean & Median & Stdev & Skew & Kurtosis & Max. & Min. & Sharpe \\
\hline \multicolumn{9}{|c|}{ Panel A: Market capitalization } \\
\hline Financials & 0.04 & 0.00 & 0.16 & 0.46 & 14.39 & 0.09 & -0.06 & 0.26 \\
\hline Industrials & 0.03 & 0.00 & 0.17 & -0.16 & 11.66 & 0.07 & -0.11 & 0.15 \\
\hline Consumer Goods & 0.03 & 0.00 & 0.18 & 0.24 & 18.54 & 0.12 & -0.13 & 0.18 \\
\hline Consumer Services & 0.14 & 0.00 & 0.24 & 0.83 & 17.38 & 0.16 & -0.13 & 0.56 \\
\hline \multicolumn{9}{|c|}{ Panel B: Book-to-market ratio } \\
\hline Financials & 0.11 & 0.00 & 0.17 & 0.70 & 13.07 & 0.09 & -0.08 & 0.65 \\
\hline Industrials & 0.08 & 0.00 & 0.19 & 0.68 & 16.11 & 0.12 & -0.09 & 0.40 \\
\hline Consumer Goods & 0.09 & 0.01 & 0.13 & 0.27 & 8.76 & 0.07 & -0.07 & 0.69 \\
\hline Consumer Services & 0.12 & 0.00 & 0.19 & 0.33 & 12.54 & 0.11 & -0.09 & 0.63 \\
\hline \multicolumn{9}{|c|}{ Panel C: Trading volume } \\
\hline Financials & 0.10 & 0.00 & 0.17 & 0.68 & 14.58 & 0.09 & -0.09 & 0.59 \\
\hline Industrials & 0.06 & 0.00 & 0.17 & 0.30 & 11.10 & 0.09 & -0.08 & 0.33 \\
\hline Consumer Goods & 0.09 & 0.00 & 0.17 & 0.26 & 14.00 & 0.10 & -0.10 & 0.55 \\
\hline Consumer Services & 0.07 & 0.00 & 0.19 & 0.19 & 7.64 & 0.09 & -0.06 & 0.40 \\
\hline
\end{tabular}

This table presents descriptive statistics of excess returns for four industry groups, controlling three different fundamental factors. We trade according to the rule that opens a position in a pair one day after price spread diverges more than $\left(1+\alpha_{1}-\gamma_{1} \alpha_{2}\right)$ units of historical standard deviation. Reported are the mean and median excess return (annualized), the (annualized) standard deviation, skew, kurtosis, the maximum and minimum daily excess return and (annualized) Sharpe ratio. The sample period is January 2000 to February 6th 2017. 
Figure 1: Price spreads between Air Liquide and BASF and pairs trading establishment
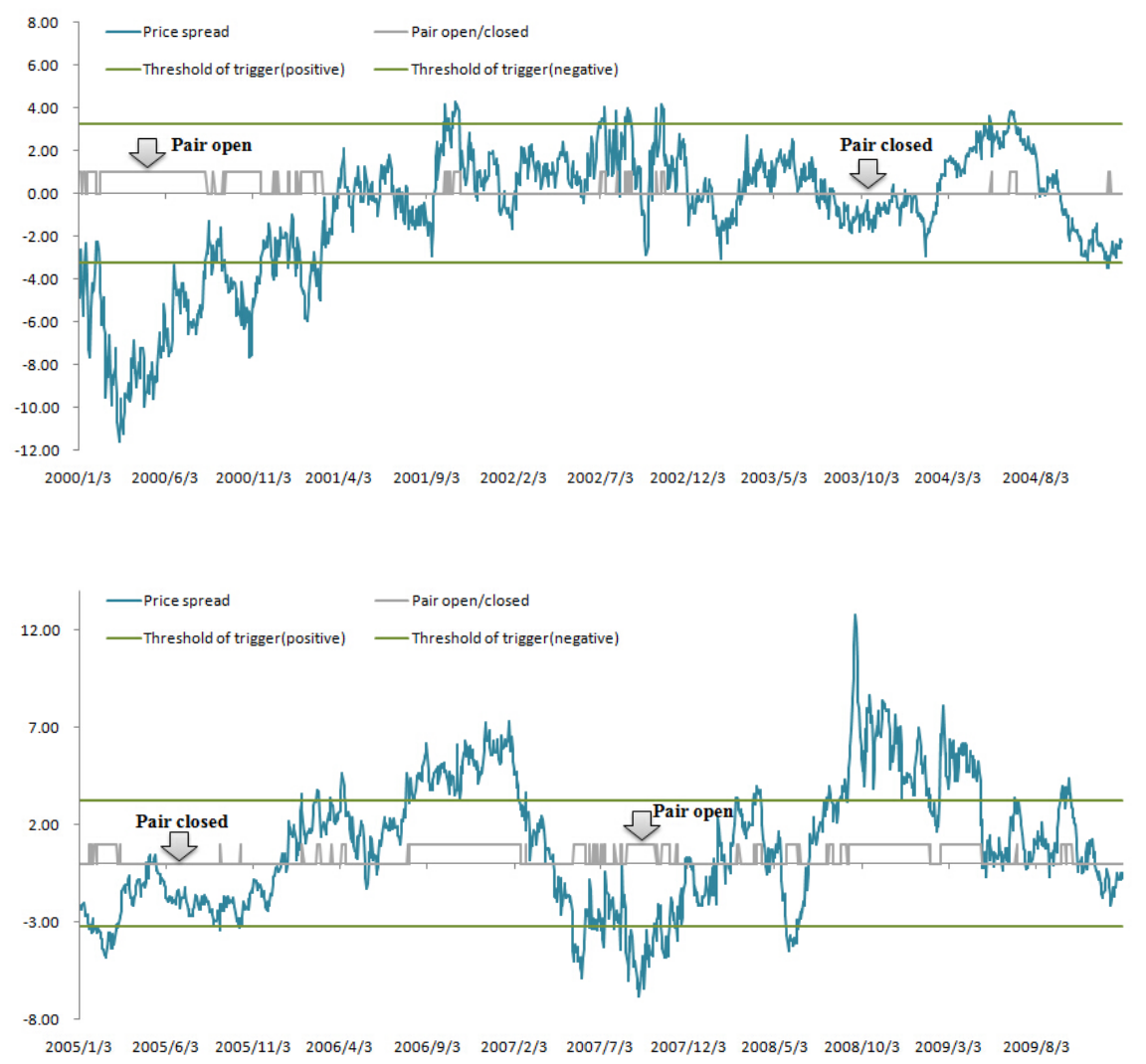

This figure illustrates how to perform pairs trading strategy using the cointegrated pair, Air Liquide and BASF, during the period 2000-2009. 
Figure 2: Cumulative returns for industry pairs portfolios and the all-pair portfolio
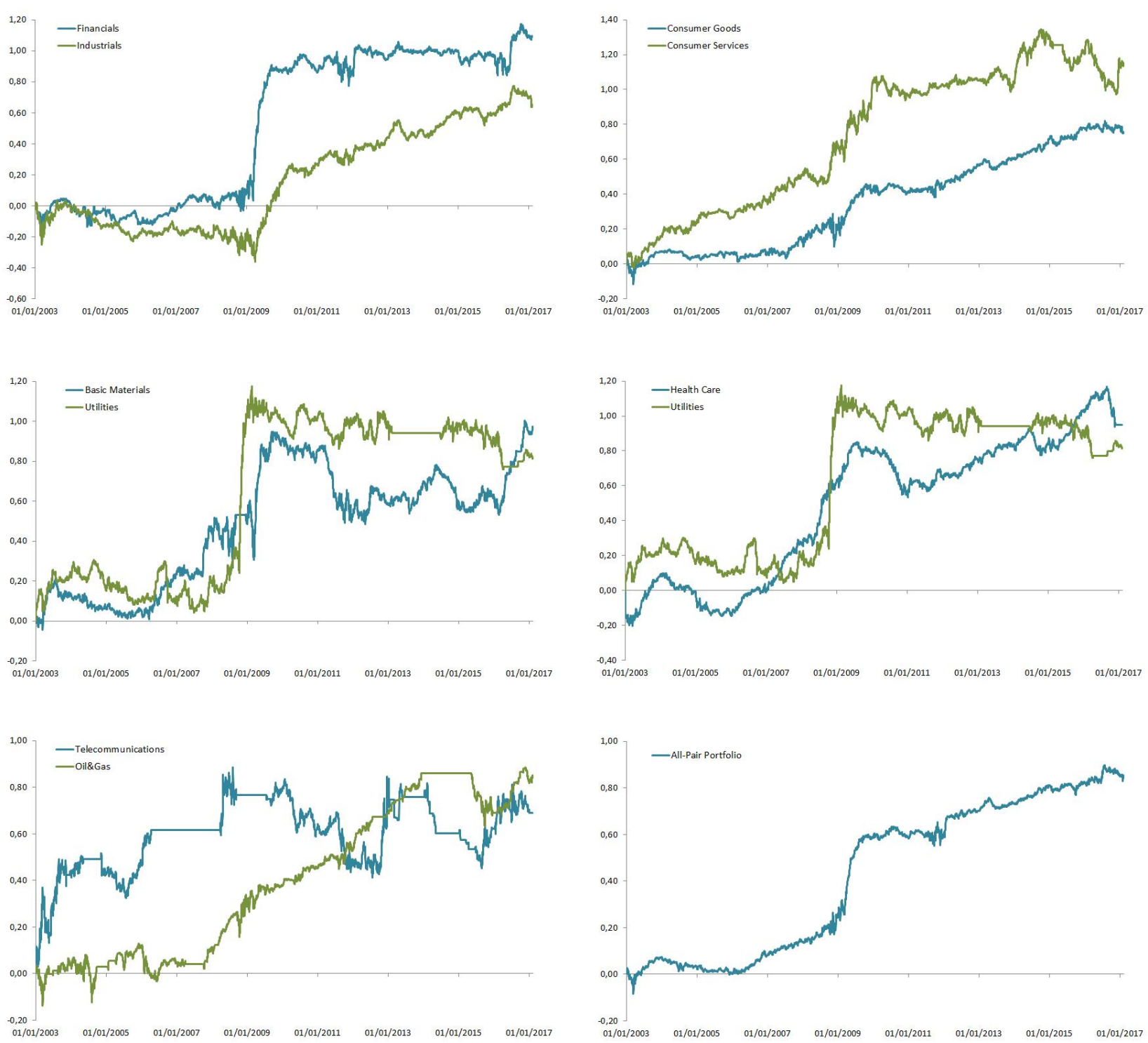

This figure plots the cumulative excess returns of equal-weighted pairs portfolios over the period January 2000 to February 6th 2017. 
Figure 3: The association of price leadership with trading volume of individual stocks

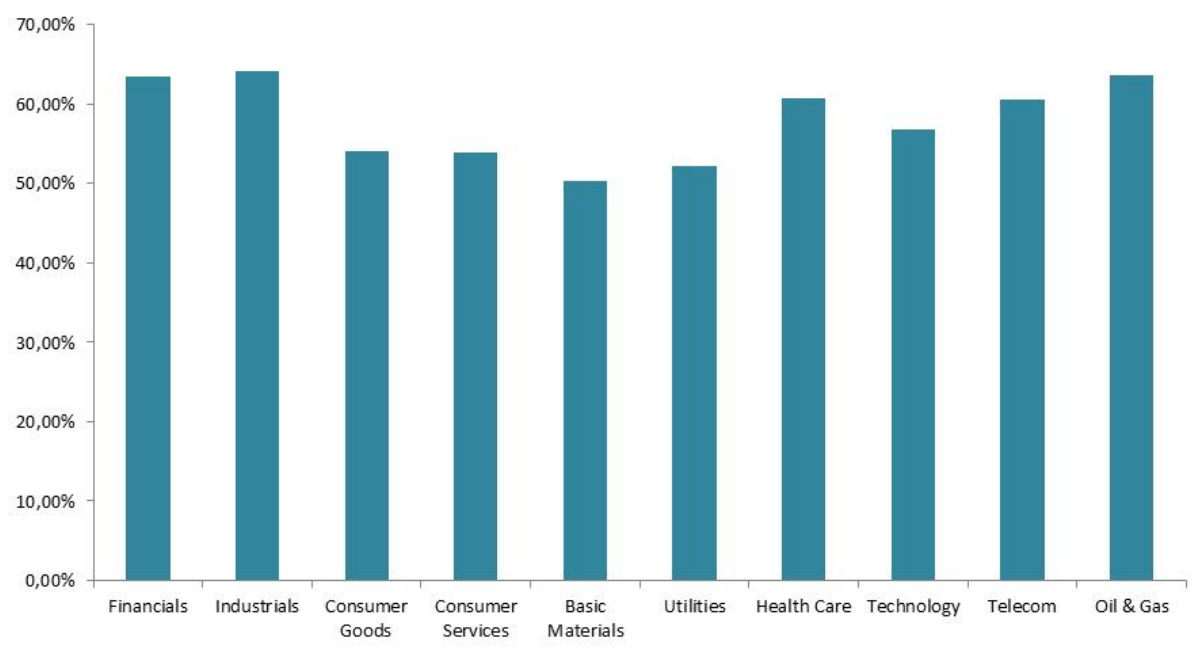

This figure shows, for each industry group, the percentage of leading assets in the price discovery process whose average trading volume is higher than the follower, over the sample period January 2000 to February 6th 2017. 